\title{
CAAS: an atmospheric correction algorithm for the remote sensing of complex waters
}

\author{
P. Shanmugam \\ Ocean optics and Imaging Laboratory, Department of Ocean Engineering, Indian Institute of Technology Madras, Chennai - \\ 600036, India
}

Correspondence to: P. Shanmugam (pshanmugam@iitm.ac.in)

Received: 31 May 2011 - Revised: 23 December 2011 - Accepted: 10 January 2012 - Published: 18 January 2012

\begin{abstract}
The current SeaDAS atmospheric correction algorithm relies on the computation of optical properties of aerosols based on radiative transfer combined with a nearinfrared (NIR) correction scheme (originally with assumptions of zero water-leaving radiance for the NIR bands) and several ancillary parameters to remove atmospheric effects in remote sensing of ocean colour. The failure of this algorithm over complex waters has been reported by many recent investigations, and can be attributed to the inadequate NIR correction and constraints for deriving aerosol optical properties whose characteristics are the most difficult to evaluate because they vary rapidly with time and space. The possibility that the aerosol and sun glint contributions can be derived in the whole spectrum of ocean colour solely from a knowledge of the total and Rayleigh-corrected radiances is developed in detail within the framework of a Complex water Atmospheric correction Algorithm Scheme (CAAS) that makes no use of ancillary parameters. The performance of the CAAS algorithm is demonstrated for MODIS/Aqua imageries of optically complex waters and yields physically realistic water-leaving radiance spectra that are not possible with the SeaDAS algorithm. A preliminary comparison with in-situ data for several regional waters (moderately complex to clear waters) shows encouraging results, with absolute errors of the CAAS algorithm closer to those of the SeaDAS algorithm. The impact of the atmospheric correction was also examined on chlorophyll retrievals with a Case 2 water bio-optical algorithm, and it was found that the CAAS algorithm outperformed the SeaDAS algorithm in terms of producing accurate pigment estimates and recovering areas previously flagged out by the later algorithm. These findings suggest that the CAAS algorithm can be used for applications focussing in quantitative assessments of the biological and biogeochemical properties in complex waters, and can easily be extended to other sensors such as OCM-2, MERIS and GOCI.
\end{abstract}

Keywords. History of geophysics (Atmospheric sciences; Ocean sciences) - Radio science (Remote sensing)

\section{Introduction}

Use of the near synoptic and global data provided by satellite sensors such as MODIS-Aqua (Moderate Resolution Imaging Spectroradiometer), MERIS (MEdium Resolution Imaging Spectrometer) and OCM2 (Ocean Colour Monitor 2) that build upon the CZCS (Coastal Zone Colour Scanner) and SeaWiFS (Sea-viewing Wide Field-of-view Sensor) heritage has become an essential component of the coastal oceanographic research and monitoring. These instruments measure the spectrum of sunlight reflected from the ocean-atmosphere system at several visible and near-infrared (NIR) wavebands. The major portion of these signals is from the contribution of scattering by molecules and particles (aerosols) in the atmosphere $(\sim 80-90 \%)$. The process of removing the atmospherically scattered signal in order to retrieve the desired ocean colour signal (i.e. water-leaving radiance $L_{\mathrm{w}}$ ) is referred to as atmospheric correction (Gordon, 1997). Since simultaneous measurements of atmospheric optical properties are not available, the atmospheric correction algorithm developed for SeaWiFS and MODIS (also referred to as SeaDAS atmospheric correction algorithm) assumes negligible $L_{\mathrm{W}}$ in the bands centred at 765 and $865 \mathrm{~nm}$ (748 and $869 \mathrm{~nm}$ in case of MODIS) in order to derive aerosol optical properties and extrapolate these into the visible spectrum (Gordon and Wang, 1994). This procedure is termed as the dark-pixel atmospheric correction scheme which has been widely used for clear ocean waters, where satisfactory results have been found with uncertainties $<5 \%$ in $L_{\mathrm{w}}$ and $<35 \%$ in chlorophyll- $a$ (Chl- $a$ ) concentrations from SeaWiFS (Hooker et al., 1992). Unfortunately, this scheme breaks 
down for optically more complex waters that are classified in the context of the present study into four types: (1) waters in the presence of intense aerosols (absorbing and nonabsorbing), (2) waters with dense phytoplankton blooms, (3) waters with high particulate (suspended matter-SS) and dissolved substances (CDOM), and (4) waters with combination of the above types and nature (all these categories belong to Case 2 waters). Though these regions are of great interest to the scientific community, resource managers and climatologists, due to errors in atmospheric correction, possibilities of determination of full spectra of water-leaving radiance are very limited and $L_{\mathrm{w}}(412)<0.2 \mathrm{~mW} \mathrm{~cm}{ }^{-2} \mu \mathrm{m}^{-1} \mathrm{sr}^{-1}$ are often excluded to minimize the impacts from atmospheric overcorrection in causing negative or significantly reduced waterleaving radiance (Siegel et al., 2002). This eventually leads to a tremendous loss of information for ocean colour work (Doerffer et al., 2008).

To overcome the black pixel assumption that progressively degrades $L_{\mathrm{W}}$ signals with increasing suspended load (SS) and algal blooms in nearshore waters, a number of authors have proposed modifications to account for non-negligible $L_{\mathrm{w}}\left(\lambda_{\mathrm{NIR} 1}\right.$ and $\left.\lambda_{\text {NIR2} 2}\right)$ within the framework of the SeaDAS atmospheric correction algorithm (Arnone et al., 1998; Ruddick et al., 2000; Siegel et al., 2000; Hu et al., 2000; Stumpf et al., 2003; Lavender et al., 2005). Relaxing the black pixel assumption through these modifications in the correction of satellite ocean colour data has shown significant improvements in the $L_{\mathrm{w}}(\lambda)$ and Chl- $a$ retrievals under normal circumstances (i.e. weak blooms/plumes and weak aerosol conditions). More recently, Wang and Shi (2007) recommended using shortwave infrared (SWIR, 1240 and $2130 \mathrm{~nm}$ ) bands for atmospheric correction of MODIS-Aqua data in moderately turbid regions. However, a decade-long time-series of $\mathrm{n} L_{\mathrm{w}}(\lambda)$ from MODIS-Aqua in complex waters (Chesapeake Bay) derived using NIR and SWIR bands for atmospheric correction demonstrates that low signal-to-noise ratios (SNR) for the SWIR bands of MODIS-Aqua added noise errors to the derived radiances, which produced broad, flat frequency distributions of $\mathrm{n} L_{\mathrm{w}}(\lambda)$ relative to those produced using the NIR bands (Werdell et al., 2010). They also noted that the SWIR approach produced an increased number of negative $\mathrm{n} L_{\mathrm{w}}(\lambda)$ and decreased sample size relative to the NIR approach. Their results imply that poor SNR values for the MODIS-Aqua SWIR bands remain the primary deficiency of the SWIR-based atmospheric correction approach. On the other hand, applying NIR and SWIR bands for atmospheric correction of MODIS-Aqua data in dense bloom waters gives nearly the same results with negatively biased $L_{\mathrm{w}}(412)$ signals for the bloomed area (Amin et al., 2009).

Many factors, such as (1) the breakdown of the black-pixel assumption in the NIR/SWIR spectral region due to algal blooms or other particles in the coastal ocean, and (2) insufficient or inadequate aerosol models adopted for atmospheric correction, influence the accuracy of atmospheric correction algorithms and thereby of ocean colour retrievals (Yan et al.,
2002). The quality of such retrievals with such algorithms becomes increasingly questionable in all four situations mentioned earlier. Additional problems and complications are encountered when optical properties of atmospheric aerosol in the considered region demonstrate very strong diversity and often do not satisfy the assumptions and invalidate a NIR approach with the SeaDAS algorithm. In particular, due to absorption effects, aerosol radiance of the desert dust is weaker at the shorter wavelengths than any of those models, and cannot be accounted for adequately (Gordon, 1997). Besides, influence of strongly absorbing aerosols shows a significant dependence on their vertical distribution. This problem has been recently considered in few studies (e.g. Moulin et al., 2001; Nobileau and Antoine, 2005). The general approach is based on the coupled modeling of the optical properties of sea water and atmospheric aerosol. Such approaches are applicable for Case 1 ocean waters only, but the complex waters do not belong to Case 1 type. An alternate method has been developed for deriving aerosol properties solely from the sensor-measured signal for atmospheric correction of SeaWiFS imagery in the presence of strongly absorbing aerosols (Shanmugam and Ahn, 2007a). While this method shows a considerable promise in retrieving reliable $L_{\mathrm{w}}(\lambda)$ values under these conditions, it requires additional data for its operational utility. Thus, it is necessary to look for a different algorithm that relies solely on the total and Rayleigh-corrected radiances to derive atmospheric properties and oceanic signals without involving many assumptions and ancillary data. The algorithm should be sensorindependent so that it can be applied to any (current and future) sensors to retrieve an unbiased estimate of $L_{\mathrm{w}}(\lambda)$ values. Merging these different sources of information into a unique dataset not only increases data availability for a certain complex area, but also increases the quality of information retrieved from the ocean (Mélin et al., 2007). Such data are highly desired by the scientific community for studying optical and biological properties of marine waters, addressing marine environmental issues, and investigating a variety of topics including marine primary productivity, ecosystem dynamics, sedimentation and pollution.

It is highly desirable to be able to effect atmospheric corrections without recourse to surface measurements. In the present paper a new atmospheric correction algorithm for complex waters (CAAS) is described in detail. The first test of this algorithm is demonstrated for few MODIS-Aqua images acquired over two complex and contrasting waters. Whereas the SeaDAS algorithm fails partly or completely for these regions, which are known to be optically very complex (turbid and algal bloom-dominated) waters, the CAAS algorithm gives qualitatively realistic spatial structure in waterleaving radiance for all available visible bands. A comparison is also made with concurrent in-situ measurements from several regional waters. 


\section{Mathematical description of the algorithm (CAAS)}

The total signal $\left(L_{\mathrm{t}}\right)$ received by a sensor at the top of the atmosphere (TOA) in a spectral band cantered at a wavelength $\lambda_{i}$, is conveniently described in terms of radiance and decomposed into the following components:

$$
L_{\mathrm{t}}\left(\lambda_{i}\right)=L_{\mathrm{p}}\left(\lambda_{i}\right)+T L_{\mathrm{sg}}\left(\lambda_{i}\right)+t L_{\mathrm{wc}}\left(\lambda_{i}\right)+t L_{\mathrm{w}}\left(\lambda_{i}\right)
$$

where $L_{\mathrm{p}}\left(\lambda_{i}\right)$ is the path radiance resulting from scattering in the atmosphere and from specular reflection of atmospherically scattered light (skylight) from the sea surface, $L_{\mathrm{sg}}\left(\lambda_{i}\right)$ is the radiance of direct sun glint from the sea surface, $L_{\mathrm{wc}}\left(\lambda_{i}\right)$ is the radiance of whitecaps at the sea surface, $L_{\mathrm{w}}\left(\lambda_{i}\right)$ is the desired water-leaving radiance, and $T\left(\lambda_{i}\right)$ and $t\left(\lambda_{i}\right)$ are the respective direct and diffuse transmittances of the atmospheric column. The whitecap contribution $L_{\mathrm{wc}}\left(\lambda_{i}\right)$ in ocean colour data can be estimated by using a previously established reflectance model with the input of sea surface wind speed (Koepke, 1984). However, Gordon and Wang (1994) noted that the whitecap reflectance model used in the SeaDAS algorithm produces unacceptable errors (overestimation of the whitecap contribution) when the sea surface wind speed is greater than $8 \mathrm{~m} \mathrm{~s}^{-1}$. This leads to the underestimation of water-leaving radiances in those regions. To avoid such a miscalculation, the whitecap contribution $L_{\mathrm{wc}}\left(\lambda_{i}\right)$ is ignored for brevity. Then, Eq. (1) reduces to

$L_{\mathrm{t}}\left(\lambda_{i}\right)=L_{\mathrm{p}}\left(\lambda_{i}\right)+T\left(\lambda_{i}\right) L_{\mathrm{sg}}\left(\lambda_{i}\right)+t\left(\lambda_{i}\right) L_{\mathrm{w}}\left(\lambda_{i}\right)$

where $L_{\mathrm{p}}\left(\lambda_{i}\right)=L_{\mathrm{r}}\left(\lambda_{i}\right)+L_{\mathrm{a}}\left(\lambda_{i}\right)+L_{\mathrm{cpl}}\left(\lambda_{i}\right)$.

The path radiance is further decomposed into the following components, assuming that radiances due to aerosol or molecular scattering are separable: $L_{\mathrm{r}}\left(\lambda_{i}\right)$, the radiances due to scattering by the air molecules (Rayleigh scattering in the absence of aerosols); $L_{\mathrm{a}}\left(\lambda_{i}\right)$, the radiances due to scattering by aerosols (in the absence of air molecules); and $L_{\mathrm{cpl}}\left(\lambda_{i}\right)$, the radiances (coupled term) due to multiple interaction between molecules and aerosols. It should be noted that $L_{\mathrm{r}}\left(\lambda_{i}\right)$ at all visible and NIR wavelengths depends on the atmospheric molecular composition, the sun and viewing geometry, and, weakly, on sea-surface roughness (Gordon et al., 1988; Gordon and Wang, 1992). Given the surface atmospheric pressure (to determine the value of $\tau_{\mathrm{r}}$ ) and surface wind speed (to determine the roughness of the sea surface), $L_{\mathrm{r}}\left(\lambda_{i}\right)$ can be computed accurately without use of the remotely sensed radiometric data (Gordon et al., 1988; Gordon and Wang, 1992). Subtraction of $L_{\mathrm{r}}\left(\lambda_{i}\right)$ from $L_{\mathrm{t}}\left(\lambda_{i}\right)$ gives the Rayleigh-corrected $\left(L_{\mathrm{rc}}\left(\lambda_{i}\right)\right)$ radiance, which is defined as

$$
\begin{aligned}
L_{\mathrm{rc}}\left(\lambda_{i}\right) & =L_{\mathrm{t}}\left(\lambda_{i}\right)-L_{\mathrm{r}}\left(\lambda_{i}\right) \\
& =L_{\mathrm{a}}\left(\lambda_{i}\right)+L_{\mathrm{cpl}}\left(\lambda_{i}\right)+T\left(\lambda_{i}\right) L_{\mathrm{sg}}\left(\lambda_{i}\right)+t\left(\lambda_{i}\right) L_{\mathrm{w}}\left(\lambda_{i}\right)
\end{aligned}
$$

Aerosol radiance cannot be obtained without a priori knowledge in a similar way, because aerosol optical properties can vary substantially over short time and space scales. Accurate estimation of $L_{\mathrm{a}}\left(\lambda_{i}\right)$ and $L_{\mathrm{cpl}}\left(\lambda_{i}\right)$ requires in-situ field measurements of aerosol type, optical thickness, air pressure, wind, water vapour, etc., at the time of each image acquisition. These measurements are frequently unavailable or are of questionable quality which makes routine and accurate atmospheric correction of satellite images with radiative transfer models difficult (Song et al., 2000). Furthermore, scattering and absorption by aerosols are difficult to characterize due to their variation in time and space (Gordon and Wang, 1994), thus constituting the most severe limitation to the atmosphere correction of satellite data (Coppin and Bauer, 1994). Thus, the SeaDAS assumes zero $\rho_{\mathrm{w}}$ for $\lambda_{\mathrm{NIR} 1}$ and $\lambda_{\mathrm{NIR} 2}$ to derive the aerosol type $\varepsilon=\rho_{\mathrm{as}}\left(\lambda_{\mathrm{NIR} 1}\right) / \rho_{\mathrm{as}}\left(\lambda_{\mathrm{NIR} 2}\right)$ (more recently assumption of zero $\rho_{\mathrm{W}}$ at NIR bands has been replaced with a NIR correction scheme, Werdell et al., 2010), uses this to select the most appropriate aerosol model from a family of $\mathrm{N}$ aerosol models for different solar and viewing geometries, and on the basis of the selected model derives aerosol information from NIR into the visible. Subtracting this from the total yields the full set of water-leaving reflectances $\rho_{(\lambda)}$, which include implicitly zero values for $\rho_{\mathrm{W}}\left(\lambda_{\mathrm{NIR} 1}\right)$ and $\rho_{\mathrm{w}}\left(\lambda_{\mathrm{NIR} 2}\right)$ and improbable large negative values for $\rho_{\mathrm{w}}\left(\lambda_{412}-\lambda_{443}\right)$ in complex waters. This problem is more severe in waters with algal blooms (e.g. Arabian Sea), where large negative values are also produced at other visible bands. To avoid a number of assumptions and further refinements needed for an extension of the SeaDAS algorithm to such waters, aerosol radiances at near-infrared bands $\left(L_{\mathrm{a}}\left(\lambda_{\mathrm{NIR} 1}\right)\right.$ and $\left.L_{\mathrm{a}}\left(\lambda_{\mathrm{NIR} 2}\right)\right)$ are iteratively derived from the spectral information of $L_{\mathrm{rc}}\left(\lambda_{i}\right)$ through the following spectral models:

$$
\left.\begin{array}{l}
L_{\mathrm{a}}\left(\lambda_{\mathrm{NIR} 1}\right)=L_{\mathrm{rc}}\left(\lambda_{\mathrm{NIR} 1}\right)-L_{\mathrm{ac}}\left(\lambda_{\mathrm{NIR} 1}\right) \\
L_{\mathrm{a}}\left(\lambda_{\mathrm{NIR} 2}\right)=L_{\mathrm{rc}}\left(\lambda_{\mathrm{NIR} 2}\right)-L_{\mathrm{ac}}\left(\lambda_{\mathrm{NIR} 2}\right)
\end{array}\right\}
$$

where aerosol corrected radiances $\left(L_{\mathrm{ac}}\right)$ for the NIR bands that are derived as follows:

$$
\begin{aligned}
L_{\mathrm{ac}}\left(\lambda_{\mathrm{NIR} 1}\right)= & \frac{L_{\mathrm{rc}}\left(\lambda_{\mathrm{NIR} 2}\right)}{L_{\mathrm{rc}}\left(\lambda_{\mathrm{NIR} 1}\right)^{2}} \times\left\{\left[\left[L_{\mathrm{rc}}\left(\lambda_{\mathrm{NIR} 1}\right)-L_{\mathrm{rc}}\left(\lambda_{\mathrm{NIR} 2}\right)\right]\right.\right. \\
& \left.\times L_{\mathrm{rc}}\left(\lambda_{\mathrm{NIR} 1}\right)\right]- \\
& {\left[\frac{L_{\mathrm{rc}}\left(\lambda_{\mathrm{NIR} 2}\right)}{\pi} \times\left[L_{\mathrm{rc}}\left(\lambda_{412}\right)-L_{\mathrm{rc}}\left(\lambda_{\mathrm{NIR} 2}\right)\right]\right.} \\
& \left.\left.\times\left[L_{\mathrm{rc}}\left(\lambda_{\mathrm{NIR} 1}\right)-L_{\mathrm{rc}}\left(\lambda_{\mathrm{NIR} 2}\right)\right]\right]\right\} \\
L_{\mathrm{ac}}\left(\lambda_{\mathrm{NIR} 2}\right)= & \frac{L_{\mathrm{ac}}\left(\lambda_{\mathrm{NIR} 1}\right)}{\pi}
\end{aligned}
$$

Because the reliable estimation of $L_{\mathrm{a}}\left(\lambda_{i}\right)$ is necessary for the visible and NIR bands, $L_{\mathrm{a}}\left(\lambda_{\mathrm{NIR} 1}\right)$ and $L_{\mathrm{a}}\left(\lambda_{\mathrm{NIR} 2}\right)$ are used in the second iteration to obtain new aerosol radiances at all wavelengths through Eqs. (7) and (8).

$L_{\mathrm{a}}\left(\lambda_{i}\right)=L_{\mathrm{rc}}\left(\lambda_{i}\right)-L_{\mathrm{ac}}\left(\lambda_{i}\right)$

$L_{\mathrm{ac}}\left(\lambda_{i}\right)=\frac{L_{\mathrm{a}}\left(\lambda_{\mathrm{NIR} 2}\right)}{L_{\mathrm{a}}\left(\lambda_{\mathrm{NIR} 1}\right)^{2}} \times\left\{\left[\left[L_{\mathrm{rc}}\left(\lambda_{i}\right)-L_{\mathrm{a}}\left(\lambda_{\mathrm{NIR} 2}\right)\right]\right.\right.$ 


$$
\begin{aligned}
& \left.\times L_{\mathrm{a}}\left(\lambda_{\mathrm{NIR} 1}\right)\right]- \\
& {\left[\frac{L_{\mathrm{a}}\left(\lambda_{\mathrm{NIR} 2}\right)}{\pi} \times\left[L_{\mathrm{rc}}\left(\lambda_{412}\right)-L_{\mathrm{a}}\left(\lambda_{\mathrm{NIR} 2}\right)\right]\right.} \\
& \left.\left.\times\left[L_{\mathrm{a}}\left(\lambda_{\mathrm{NIR} 1}\right)-L_{\mathrm{a}}\left(\lambda_{\mathrm{NIR} 2}\right)\right]\right]\right\}
\end{aligned}
$$

The estimates of $L_{\mathrm{a}}\left(\lambda_{i}\right)$ are reasonably comparable with those of the SeaDAS algorithm for open ocean waters where aerosols occur locally. However, for coastal waters $L_{\mathrm{a}}\left(\lambda_{i}\right)$ derived from CAAS differ with those of the SeaDAS algorithm because these regions usually have both Case 2 waters in which the $\rho_{\mathrm{w}}$ at the two NIR bands are discarded or the estimated $\rho_{\mathrm{w}}$ in these bands are insufficient to deal with bloom/turbid waters and strongly absorbing aerosols (Shanmugam and Ahn, 2007a, b).

One of the major confounding factors limiting the quality and accuracy of ocean colour data is sun glint, the specular reflection of directly transmitted sunlight from the upper side of the air-water interface (Doerffer et al., 2008; Kay et al., 2009). The sun glint correction is an extension of the atmospheric correction. Data of sensors such as MODIS, MERIS and OCM2, which have no capability to tilt the sensor in forward or backward direction to avoid or reduce the influence of sun glint, are contaminated with glint patterns, which may often cover more than half of the image. Without an accurate correction these data are lost for retrieving optical properties of the water or the concentrations of substances (Doerffer et al., 2008). Its distribution depends on the solar and observation angles and the roughness of the sea (wind dependent wave slopes), and can be defined as follows:

$n L_{\mathrm{sg}}\left(\lambda_{i}\right)=\frac{L_{\mathrm{sg}}\left(\lambda_{i}\right)}{T\left(\lambda_{i}\right)}$

where $n L_{\mathrm{sg}}\left(\lambda_{i}\right)$ is the normalized sun glint radiance and $T\left(\lambda_{i}\right)$ is assumed unity. Though methods based on the Cox and Munk model are used with most of the ocean colour instruments now in operation they do have limitations. The wind data may not have sufficient resolution to capture the effects of local winds, and the Cox and Munk model does not include the effects of atmospheric stability, wind age or swell (Hwang and Shemdin, 1988). Furthermore, aerosol values are particularly hard to separate from the glint signal, since the "effect" that increases with aerosol load is not the glint itself but the error due to the single scattering approximation (Kay et al., 2009). To estimate the sun glint radiance $\left(L_{\mathrm{sg}}\right)$, the model involves measurements of $L_{\mathrm{a}}\left(\lambda_{412}\right)$, $L_{\mathrm{ac}}\left(\lambda_{412}\right), L_{\mathrm{t}}\left(\lambda_{412}\right)$, and $L_{\mathrm{rc}}\left(\lambda_{412}\right)$ (assuming glint information contained in all these products) to calculate $L_{\mathrm{sg}}$ at $412 \mathrm{~nm}$ with the following criteria:

$L_{\mathrm{sg}}\left(\lambda_{412}\right)=\frac{L_{\mathrm{rc}}\left(\lambda_{412}\right)}{L_{\mathrm{t}}\left(\lambda_{412}\right)} \times\left[L_{\mathrm{a}}\left(\lambda_{412}\right)-L_{\mathrm{ac}}\left(\lambda_{412}\right)\right]$

If $L_{\mathrm{sg}}<0$

$L_{\mathrm{sgc}}\left(\lambda_{i}\right)=L_{\mathrm{ac}}\left(\lambda_{i}\right)$ where $i=412 \sim 551$.

If $L_{\mathrm{sg}}>0$

$L_{\mathrm{sgc}}\left(\lambda_{i}\right)=L_{\mathrm{ac}}\left(\lambda_{i}\right)-L_{\mathrm{sg}}\left(\lambda_{i}\right)$

where $i=412 \sim 551$.

The relative amount of sun glint $L_{\mathrm{sg}}\left(\lambda_{i}\right)$ can be obtained by an exponential function with $L_{\mathrm{sg}}\left(\lambda_{412}\right)$ as an input;

$L_{\mathrm{sg}}\left(\lambda_{i}\right)=L_{\mathrm{sg}}\left(\lambda_{412}\right) \times \exp \left(\lambda_{i} / \lambda_{869}\right)$

Our analysis shows that the slightly higher values of $L_{\mathrm{sg}}\left(\lambda_{412}\right)$ from Eq. (11) are adequate for its correction at longer wavelengths $\left(\lambda_{667}-\lambda_{869}\right.$ with similar criteria). The sun glint corrected radiance $L_{\mathrm{sgc}}\left(\lambda_{i}\right)$ is as follows:

$$
\begin{aligned}
L_{\mathrm{sgc}}\left(\lambda_{i}\right) & =L_{\mathrm{t}}\left(\lambda_{i}\right)-L_{\mathrm{r}}\left(\lambda_{i}\right)-L_{\mathrm{a}}\left(\lambda_{i}\right)-T\left(\lambda_{i}\right) L_{\mathrm{sg}}\left(\lambda_{i}\right) \\
& =L_{\mathrm{cpl}}\left(\lambda_{i}\right)+t\left(\lambda_{i}\right) L_{\mathrm{w}}\left(\lambda_{i}\right)
\end{aligned}
$$

The water-leaving radiance $t\left(\lambda_{i}\right) L_{\mathrm{w}}\left(\lambda_{i}\right)$ exiting the TOA can be retrieved if the coupled aerosol term $L_{\mathrm{cpl}}\left(\lambda_{i}\right)$ is known. However, this component is very complex and its estimation is critical because it often deteriorates the accuracy of $L_{\mathrm{W}}\left(\lambda_{i}\right)$ (Gordon and Voss, 1999). Removal of $L_{c p l}\left(\lambda_{i}\right)$ can be achieved through a spectral model that takes the following form of equation to provide estimates of $t\left(\lambda_{i}\right) L_{\mathrm{W}}\left(\lambda_{i}\right)$ :

$$
\begin{aligned}
t\left(\lambda_{i}\right) L_{\mathrm{W}}\left(\lambda_{i}\right)= & {\left[\left(\left(v\left(\lambda_{i}\right)\right)^{\left(\lambda_{i} / \lambda_{\mathrm{NIR} 2}\right)} v^{\prime}\left(\lambda_{i}\right)\right)\left(\frac{\lambda_{412}}{\lambda_{\mathrm{NIR} 2}}\right)\right] } \\
& -\left[\Delta \varepsilon\left(\lambda_{i}, \lambda_{\mathrm{NIR} 2}\right) \times L_{\mathrm{a}}\left(\lambda_{\mathrm{NIR} 2}\right)\right]
\end{aligned}
$$

The $\left(v\left(\lambda_{i}\right)\right)^{\left(\lambda_{i} / \lambda_{\mathrm{NIR} 2}\right)}$ and $v^{\prime}\left(\lambda_{i}\right)$ are obtained independently with two models that behave quite differently according to:

$v\left(\lambda_{i}\right)=L_{\mathrm{sgc}}\left(\lambda_{i}\right)-\frac{L_{\mathrm{a}}\left(\lambda_{i}\right)-L_{\mathrm{rc}}\left(\lambda_{i}\right)}{L_{\mathrm{rc}}\left(\lambda_{i}\right)-L_{\mathrm{sgc}}\left(\lambda_{i}\right)}$
$v^{\prime}\left(\lambda_{i}\right)=L_{\mathrm{sgc}}\left(\lambda_{i}\right)-\left[-\left(\frac{L_{\mathrm{a}}\left(\lambda_{i}\right)-L_{\mathrm{a}}\left(\lambda_{\mathrm{NIR} 2}\right)}{L_{\mathrm{rc}}\left(\lambda_{i}\right)-L_{\mathrm{sgc}}\left(\lambda_{i}\right)}\right)\right]$

The above corrections are necessary because the aerosols are many types (strongly absorbing and non-absorbing) and may consist of a multi-component mixture of particles with different chemical compositions (that change with differing humidity and altitude) and affinities to water (Yan et al., 2003). It has been noted that under these circumstances, models with the SeaDAS algorithm remove too much $L_{\mathrm{cpl}}\left(\lambda_{i}\right)$ from sensor-observed radiance which eventually leads to a nonnegligible error in the retrieval of ocean colour ( $\mathrm{Li}$ et al., 2003). The above spectral models (Eqs. 14 and 15) overcome a number of shortcomings, thereby deriving and effectively removing most, if not all, of the $L_{\mathrm{cpl}}\left(\lambda_{i}\right)$ contribution. However, they spectrally alter the resulting products as well, but such effects can be corrected by modifying the amplitude of $v\left(\lambda_{i}\right)$ based on a wavelength-dependent variable $\left(\lambda_{i} / \lambda_{\mathrm{NIR} 2}\right)$ (no modification is warranted to the $v^{\prime}\left(\lambda_{i}\right)$ ). This procedure is however preceded by an essential correction to the $v\left(\lambda_{412}\right)$ at which the available signal $L_{\mathrm{rc}}\left(\lambda_{i}\right)$ is very low and even 
goes negative due to the sensitivity and digitization errors in turbid/highly productive waters (e.g. dense algal blooms). Thus, the following correction is applied to that wavelength:

$v\left(\lambda_{412}\right)=\frac{\left[\frac{v\left(\lambda_{443}\right)-v\left(\lambda_{412}\right)}{\lambda_{443}-\lambda_{412}}\right]+v\left(\lambda_{443}\right)}{2}$

Subsequently, the initial estimates of $v\left(\lambda_{412}\right)$ are replaced by these new values regardless of the signal level in different waters. A similar correction should be extended to the $v^{\prime}\left(\lambda_{412}\right)$ product, only if this product includes implicitly negative values for $412 \mathrm{~nm}$ (i.e. pixels having $v^{\prime}\left(\lambda_{412}\right)<$ $0)$. Finally, spectral stability of the combined products over the short and long wavelengths $(412-869 \mathrm{~nm}$ in case of MODIS/Aqua) is achieved by adopting a constant $\lambda_{412} / \lambda_{\text {NIR2 }}$ in Eq. (13).

The residual scattering component may nonetheless remain and can be estimated using an exponential relationship for the spectral behaviour of aerosol optical depth (Gordon and Wang, 1994). The derived values are reduced by a factor of 0.075 for $\lambda<700 \mathrm{~nm}$ and 0.05 for $\lambda>700 \mathrm{~nm}$, as follows:

$$
\begin{aligned}
\Delta \varepsilon\left(\lambda_{i}, \lambda_{\mathrm{NIR} 2}\right)= & \exp \left(\left[\frac{\left(\lambda_{\mathrm{NIR} 2}-\lambda_{i}\right)}{\left(\lambda_{\mathrm{NIR} 2}-\lambda_{\mathrm{NIR} 1}\right)}\right]\right. \\
& \left.\times \log _{\mathrm{e}}\left[\frac{L_{\mathrm{a}}\left(\lambda_{\mathrm{NIR} 2}\right)}{L_{\mathrm{a}}\left(\lambda_{\mathrm{NIR} 1}\right)}\right]\right) \times I_{0}
\end{aligned}
$$

where, $I_{0}=0.075$ for $i=412 \sim 678, I_{0}=0.05$ for $i=$ NIR 1 , NIR2.

This is a slightly modified form of equation applicable only for the correction of residual effects of aerosol scattering in the $\mathrm{t} L_{\mathrm{w}}$ products. Note that radiance exits the water and enters the atmosphere in all upward directions. It is then modified by the atmosphere through absorption and scattering and exits the TOA, where it is measured by the sensor. This means that to derive the desired water-leaving radiance, the diffuse transmittance $t\left(\lambda_{i}\right)$ is required. The current SeaDAS atmospheric correction algorithm devised for SeaWiFS/MODIS-Aqua enables a good approximation of $t\left(\lambda_{i}\right)$ values from LUTs for a given aerosol model in the form:

$t\left(\theta_{\mathrm{v}} \lambda_{i}\right)=A\left(\theta_{\mathrm{v}} \lambda_{i}\right) \exp \left[-B\left(\theta_{\mathrm{v}} \lambda_{i}\right) \tau_{\mathrm{a}}\left(\lambda_{i}\right)\right]$

where $A\left(\theta_{\mathrm{v}} \lambda_{i}\right)$ and $B\left(\theta_{\mathrm{v}} \lambda_{i}\right)$ are the fitting coefficients and $\tau_{\mathrm{a}}(\lambda)_{i}$ is the aerosol optical thickness. Note that the values produced from this model mostly range from 0.75 in the blue and 1 in the NIR. The $t\left(\lambda_{i}\right)$ values from the tables are accurate (within $0.1 \%$, Wang, 1999) giving:

$\left[L_{\mathrm{W}}\left(\lambda_{i}\right)\right]_{N}=L_{\mathrm{w}}\left(\lambda_{i}\right) / t\left(\lambda_{i}\right)$

In order to improve the quality and accuracy of $\left[L_{\mathrm{w}}\left(\lambda_{i}\right)\right]_{N}$, an iterative spectral shape matching scheme is developed based on the in-situ measurements from clear, turbid and algal bloom waters. This scheme attempts to fine tune the satellite-derived $\left[L_{\mathrm{w}}\left(\lambda_{i}\right)\right]_{N}$ values to match with measurements from all these water types, and makes such retrievals independent of the model of diffuse transmittance proposed by Gordon and Wang (1994) and Wang (1999). A set of equations determined from this scheme can be used to convert $\left[L_{\mathrm{w}}\left(\lambda_{i}\right)\right]_{N}$ values to new $\left[L_{\mathrm{w}}\left(\lambda_{i}\right)\right]_{N}$ values as shown in Fig. 1. The new $\left[L_{\mathrm{w}}\left(\lambda_{i}\right)\right]_{N}$ can easily be converted to normalized water-leaving reflectance through

$\left[\rho_{\mathrm{W}}\left(\lambda_{i}\right)\right]_{N}=\frac{\pi}{F_{0}\left(\lambda_{i}\right)}\left[L_{\mathrm{w}}\left(\lambda_{i}\right)\right]_{N}$

where $F_{0}$ is the mean extraterrestrial solar irradiance. It should be noted that many algorithms use remote sensing reflectance $\left(R_{\mathrm{rs}}=L_{\mathrm{w}} / E_{\mathrm{d}}\right.$, where $E_{\mathrm{d}}$ is the downward irradiance just above the sea surface) rather than $\left[\rho_{\mathrm{w}}\right]_{N}$ or $\left[L_{\mathrm{w}}\right]_{N}$ (O'Reilly et al., 1998). However, to a good approximation $\left[\rho_{\mathrm{w}}\right]_{N}=\pi R_{\mathrm{rs}}$ (Gordon and Voss, 1999; Shanmugam and Ahn, 2007a). It should be noted that these spectral models and coefficients (Eqs. 4-17 and Fig. 1) of the CAAS algorithm described above are different from those of the SeaDAS scheme, and work well regardless of the nature of complex situations in different regions.

\section{Data and methods}

\subsection{In-situ data}

To assess efficacy of CAAS algorithm, the resultant products of this algorithm and SeaDAS algorithm are compared with in-situ radiometric measurements (at key wavelengths) and chlorophyll concentrations obtained from the NOMAD database (NASA bio-Optical Marine Algorithm Data set, Werdell and Bailey, 2005) for different regions around the world. These data are high quality in-situ bio-optical datasets collected over a wide range of optical properties, trophic status, and geographical locations in open ocean waters, estuaries, and coastal waters. Despite these data encompass large samples, only few cruises data were used consisting of 57 radiometric and pigment measurements collected between 2003 and 2007 in various regional waters (Cruises TANK2, FLA_KEYS, WFS, 2004, 2005, 2006 and 2007, for which Chl ranged from 0.15 to $5.9 \mathrm{mg} \mathrm{m}^{-3}$ ). Dates when satellite sampling for a given station was masked by clouds or affected by sensor digitization problems were excluded from the analysis.

\subsection{Satellite data and processing}

MODIS-Aqua Level 1A data ( $\sim 1 \mathrm{~km}$ pixel $^{-1}$ at nadir, LAClocal area coverage) corresponding to the above in-situ measurements were obtained from the NASA Goddard Space Flight Centre (http://oceancolor.gsfc.nasa.gov/). Besides, four other MODIS-Aqua scenes (19 February 2008, 23 November 2008, 18 February 2010 and 4 December 2010) acquired more recently over optically very complex waters of the Arabian Sea and around Korea (Yellow Sea - YS, East China Sea - ECS and coastal waters around Korea) were 


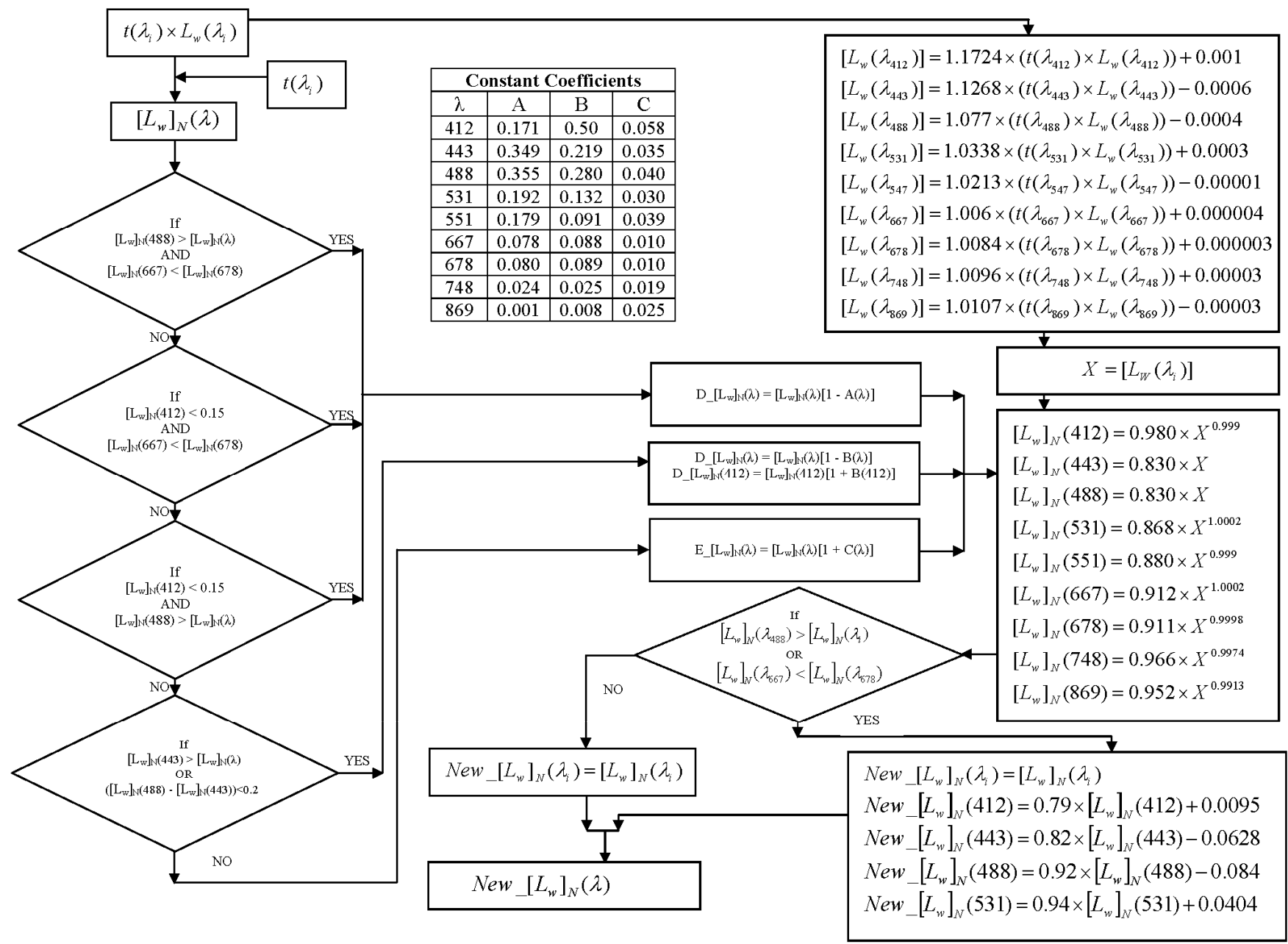

Fig. 1. Schematic representation of an iterative spectral matching scheme of the CAAS algorithm.

also obtained for assessing the performance of CAAS and SeaDAS algorithms. First, the MODIS L1A data that consisted of calibrated and scaled top of atmospheric radiances $\left(L_{\mathrm{t}}(\lambda)\right)$ were input to the SeaDAS atmospheric correction code to output the Rayleigh-corrected $\left(L_{\mathrm{rc}}(\lambda)\right)$ radiances at all wavelengths. Both $L_{\mathrm{t}}(\lambda)$ and $L_{\mathrm{rc}}(\lambda)$ were input to the CAAS algorithm to retrieve the desired water-leaving radiance products. Before applying these corrections, an operational cloud-masking scheme for all MODIS-Aqua data (except 4 December 2010 scene, which we discuss in a later section) was adopted to create flags over the cloud-covered regions. The resulting products were converted to the remote sensing reflectance $\left(R_{\mathrm{rs}}\right)$ and the pigment concentrations were estimated using a Case 2 water bio-optical algorithm proposed by Aiken et al. (1995) (also found in Carder et al., 2003). This is called the "empirically-derived or "default" algorithm which uses the $R_{\mathrm{rs}}(488) / R_{\mathrm{rs}}(551)$ ratio for chlorophyll determination. A large number data used for deriving this algorithm came from riverine-influenced and coastal waters, and therefore resulted in a best fit regres- sion with a set of coefficients as described in Table 1 . The SeaDAS $R_{\mathrm{rs}}$ and their chlorophyll products were also derived and examined in a similar way.

\section{Results and discussion}

\subsection{Application to MODIS-Aqua imagery}

\subsubsection{Image comparisons}

Implementation of the CAAS and SeaDAS algorithms to two MODIS-Aqua images (18 February 2010 and 4 December 2010) from Arabian Sea and waters around Korea (ECS, YS, Bohai Sea, and ES) enables the importance of the new algorithm to be put in context. These two scenes were selected to be good examples as these data illustrate two contrasting complex situations with desert dust aerosols as the dominant factor controlling their atmospheric conditions. Figure $2 \mathrm{a}$ displays a true colour composite (Band 253) for the Arabian Sea which demonstrates how this region is contaminated by 
Table 1. Comparison of algorithm performances using MODIS-Aqua $R_{\mathrm{rs}}$ (from SeaDAS and CAAS algorithms) and coincidently measured (in situ) $R_{\mathrm{rs}}$ (NOMAD data sets). Note that the in-situ measurements are made at 412, 443, 490, 555 and $670 \mathrm{~nm}$.

\begin{tabular}{crlrrrr}
\hline Wavelength (nm) & MRE & RMSE & SLOPE & $R^{2}$ & BIAS & $N$ \\
\hline \multicolumn{7}{c}{ CAAS $R_{\mathrm{rs}}$} \\
\hline 412 & 0.0146 & 0.2660 & 0.4701 & 0.1348 & 0.0379 & 55 \\
443 & -0.0234 & 0.2332 & 0.8029 & 0.2697 & -0.0595 & 55 \\
488 & -0.0096 & 0.1599 & 1.1417 & 0.6601 & -0.0233 & 55 \\
551 & 0.0142 & 0.1455 & 0.8802 & 0.7207 & 0.0344 & 55 \\
667 & 0.0217 & 0.1436 & 0.8392 & 0.7776 & 0.0527 & 55 \\
\hline \multicolumn{7}{c}{ SeaDAS $R_{\mathrm{rs}}$} \\
\hline 412 & 0.0123 & 0.2339 & 0.6261 & 0.3065 & 0.0318 & 55 \\
443 & -0.0058 & 0.1743 & 0.9596 & 0.5571 & -0.0149 & 55 \\
488 & 0.0043 & 0.1132 & 1.0456 & 0.8237 & 0.0105 & 55 \\
551 & -0.0016 & 0.1130 & 0.9146 & 0.8199 & -0.0040 & 55 \\
667 & 0.0052 & 0.0970 & 0.9122 & 0.8776 & 0.0127 & 55 \\
\hline \multicolumn{7}{c}{ Chlorophyll } \\
CAAS_Aiken_Chl & 4.2947 & 0.3807 & 0.8470 & 0.5301 & -0.1554 & 55 \\
SeaDAS_Aiken_Chl & 4.3279 & 0.3340 & 0.8653 & 0.6612 & -0.1566 & 55 \\
\hline
\end{tabular}

Aiken_Chl $=10^{\left(0.2818-2.783 \times R+1.863 \times R^{2}-2.387 \times R^{3}\right)}$, where $R=\log _{10}\left[R_{\mathrm{rs}}(488) / R_{\mathrm{rS}}(551)\right]$

sun glint in the central part and furthermore contaminated by haze, desert dust and strip of clouds. It is apparent that the density of this mineral (desert) dust is not uniform, and it is very strong in the vicinity of desert coasts and across the Arabian Sea. The corresponding true colour composite atmospherically corrected by the CAAS algorithm removes all these effects (Fig. 2b) and becomes more comprehensive to demonstrate that large-scale Noctiluca miliaris blooms developed in the Gulf of Oman and mesoscale eddies that populated the western Arabian Sea during the winter monsoon contributed to the genesis and dispersal of these blooms from the Gulf of Oman into the central Arabian Sea (Gomes et al., 2008). The green features in the nearshore and offshore waters are well characterized by weaker radiances in the blue band, while the brighter features relate to highly reflective materials along the coastal areas (especially Gujarat in the eastern Arabian Sea) caused by strong radiance in the green band. These episodic high values of radiance in the green are indicative of high particle loads supporting its use as a plume indicator with satellite data sets (Otero and Siegel, 2004).

A true colour MODIS-Aqua image (4 December 2010) around Korea also displays intense Yellow dust aerosols (from Gobi desert) covering a vast space with a pronounced variability over the YS and ECS and around Korea (Fig. 3a). It becomes evident that the estuary of Yangtze River and Bohai Sea are the most turbid sea areas in this region, where the SS concentration can go up to $30 \mathrm{~kg} \mathrm{~m}^{-3}$ and water-leaving radiance at $765 \mathrm{~nm}$ up to $4.5 \mathrm{~mW} \mathrm{~cm}^{-2} \mu \mathrm{m}^{-1} \mathrm{sr}^{-1}$ (Xianqiang et al., 2004). As a consequence, most of the scene, which was derived with the SeaDAS algorithm, is flagged out due to these difficult conditions (Fig. 3b). This problem could also be linked to the cloud-masking threshold with SeaDAS that often identifies the hazy and turbid atmosphere as clouds (Hu, 2009). Thus, the present threshold was relaxed in our data processing and useful ocean colour retrieval could be achieved with the CAAS algorithm. As expected, the CAAS performed very well in removing complex atmospheric conditions and achieving rather more realistic spatial structure in water-leaving radiance maps for the entire area which was previously flagged out by the SeaDAS algorithm. The spatial structures observed in Fig. $3 \mathrm{c}$ also correlate well with known SS distributions. It should be noted that the threshold for cloud detection needs to be enhanced for more complex water applications, because the assumption of low near-infrared water-leaving radiance is no longer valid (Ruddick et al., 2000).

\subsubsection{Spectral analysis}

Spectral analysis is a very useful part to examine any consequences of the CAAS and SeaDAS algorithms on the spectral features of $L_{\mathrm{w}}(\lambda)$ retrieved from MODIS-Aqua data. For this preliminary comparison, a group of $\left[L_{\mathrm{w}}\right]_{N}$ and $L_{\mathrm{rc}}(\lambda)$ spectra collected from two locations (marked by arrows in Figs. $2 b$ and $3 c$ ) for both CAAS and SeaDAS algorithms are shown in Fig. 4 (a-c: for bloom waters in the northern Arabian Sea; d-f: for SS waters in the Korean Southwest Sea). It is important to note that the $L_{\mathrm{rc}}(\lambda)$ values of bloom waters are significantly low at $412 \mathrm{~nm}$, but sharply increase in the 


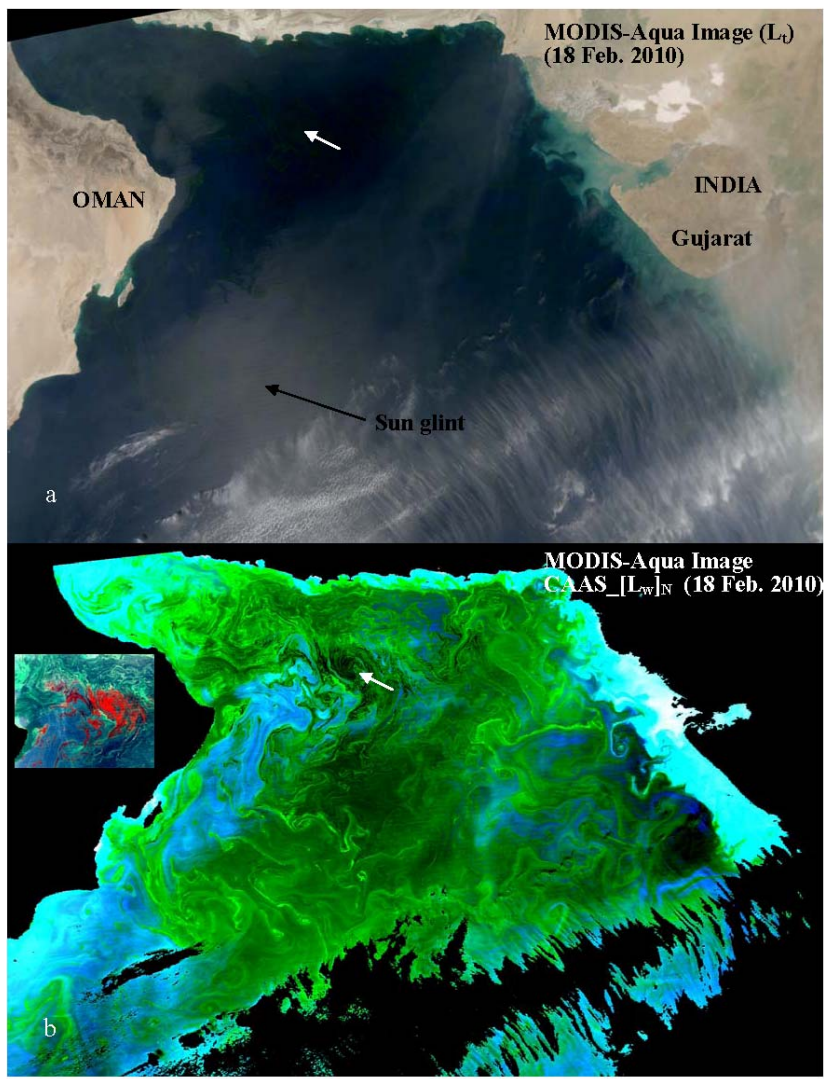

Fig. 2. MODIS-Aqua true colour composite imagery (18 February 2010) for the Arabian Sea generated from the total radiances at 443,551 and $488 \mathrm{~nm}$ (B253) (a) and the corresponding waterleaving radiance imagery from the CAAS algorithm (b). Subset image generated from the $\left[L_{\mathrm{W}}\right]_{N}$ at 748, 678 and $667 \mathrm{~nm}$ (Band 876) are displayed on the left side of the bottom panel confirming highly concentrated patches of algal blooms in the northern central Arabian Sea.

NIR (748 nm) similar to land vegetation. This ocean feature is a typical of highly concentrated or floating algal blooms (see a subset on Fig. 2b). Most of these spectra present always non-zero values at the NIR bands and near-zero values (sometime negatives) at the short-wavelengths bands (e.g. $412 \mathrm{~nm}$ ), meaning that an assumption of zero $\rho_{\mathrm{w}}$ at NIR or an updated SeaDAS algorithm with a NIR correction scheme can be easily invalidated by these conditions. Comparisons between the CAAS and SeaDAS algorithms clearly demonstrate large anomalous differences in their $\left[L_{\mathrm{w}}\right]_{N}$ spectra collected from waters with dense algal blooms, i.e. large distortions in $\left[L_{\mathrm{w}}\right]_{N}$ structures with high negative values across the wavebands revealed by the SeaDAS algorithm. According to the true colour composite image in Fig. 2a (around a white arrow mark), the atmosphere was rather clear on 18 February 2010 but the SeaDAS algorithm produced $\left[L_{\mathrm{w}}\right]_{N}$ values reaching as low as $-0.64 \mathrm{~mW} \mathrm{~cm}{ }^{-2} \mu \mathrm{m}^{-1} \mathrm{sr}^{-1}$ at $412 \mathrm{~nm}$ and $-0.23 \mathrm{~mW} \mathrm{~cm}^{-2} \mu \mathrm{m}^{-1} \mathrm{sr}^{-1}$ at $667 \mathrm{~nm}$. The dramatic anomalous negative $\left[L_{\mathrm{w}}\right]_{N}$ values could be attributed to the black-pixel assumption or inadequacy of the NIR correction scheme with the SeaDAS algorithm. The consequence of these problems could also be observed in a recent study, where the MODIS-Aqua derived $\mathrm{Chl}$ and $\mathrm{n} L_{\mathrm{w}}(443)$ data over Arabian Sea waters were flagged out by the SWIR and NIRSWIR schemes due to complex conditions (see Fig. 6 in Wang, 2009). This indicates that a simple relaxation of the black pixel assumption alone is not sufficient to improve retrievals of $\left[L_{\mathrm{w}}\right]_{N}$ at the shorter wavelengths, and other components of the processing chain may also require refinement if reliable $\left[L_{\mathrm{w}}\right]_{N}$ in this domain are to be achieved (Ruddick et al., 2000). By contrast, the CAAS algorithm outperformed the SeaDAS algorithm in terms of successfully removing most atmospheric effects and producing non-zero $\left[L_{\mathrm{w}}\right]_{N}$ values for these dense blooms. It becomes conspicuous that with increasing absorption at $443 \mathrm{~nm}$, a primary peak shifts from blue to green and a secondary peak from red to NIR in Fig. 4c. The secondary peak suggests that the concentrations of dense or floating algal blooms can be possibly mapped and quantified with a suitable bio-optical algorithm combined with the CAAS algorithm.

Figure $4 \mathrm{~d}-\mathrm{f}$ shows the Rayleigh collected spectra and their corresponding $\left[L_{\mathrm{w}}\right]_{N}$ spectra obtained with the CAAS and SeaDAS algorithms in turbid waters around the Korean Southwest Sea (as indicated by arrow in Fig. 3c). Contrary to bloomed waters, the correlation between the $L_{\mathrm{rc}}(\lambda)$ and $\left[L_{\mathrm{w}}\right]_{N}$ is noticeable in turbid waters, because these pixels are relatively free of aerosols and dominated by SS concentrations. Thus, there is consistency in $\left[L_{\mathrm{w}}\right]_{N}$ structure obtained with these algorithms, although the CAAS algorithm produced slightly low values across the wavelengths. Note that the effect of atmospheric correction with the SeaDAS algorithm on lowering radiance values is clearly seen in $\left[L_{\mathrm{w}}\right]_{N}$ spectra at $412 \mathrm{~nm}$, as opposed by the results of the CAAS algorithm (Fig. 4e and f).

Similar comparisons are also demonstrated for MODISAqua imagery of 4 December 2010 in turbid and bloomed waters of the ECS (Fig. 5). For turbid water pixels (a and b) the SeaDAS algorithm produced nearly similar spectra as those of the CAAS algorithm, but its $\left[L_{\mathrm{w}}\right]_{N}$ values reach near zero at $412 \mathrm{~nm}$. The underestimation at this wavelength suggests insufficiency of the NIR correction scheme with the SeaDAS algorithm for turbid waters (Ruddick et al., 2000; Shanmugam and Ahn, 2007a; Hu, 2009). By contrast, the effect of the CAAS algorithm on raising radiance values particularly at $412 \mathrm{~nm}$ is clearly seen and the physically realistic shape of $\left[L_{\mathrm{w}}\right]_{N}$ spectra from this algorithm is also typical for waters with dense phytoplankton blooms (d), whereas the SeaDAS algorithm simply breaks down in retrieving the physically realistic $\left[L_{\mathrm{w}}\right]_{N}$ values in bloomed waters (c). 


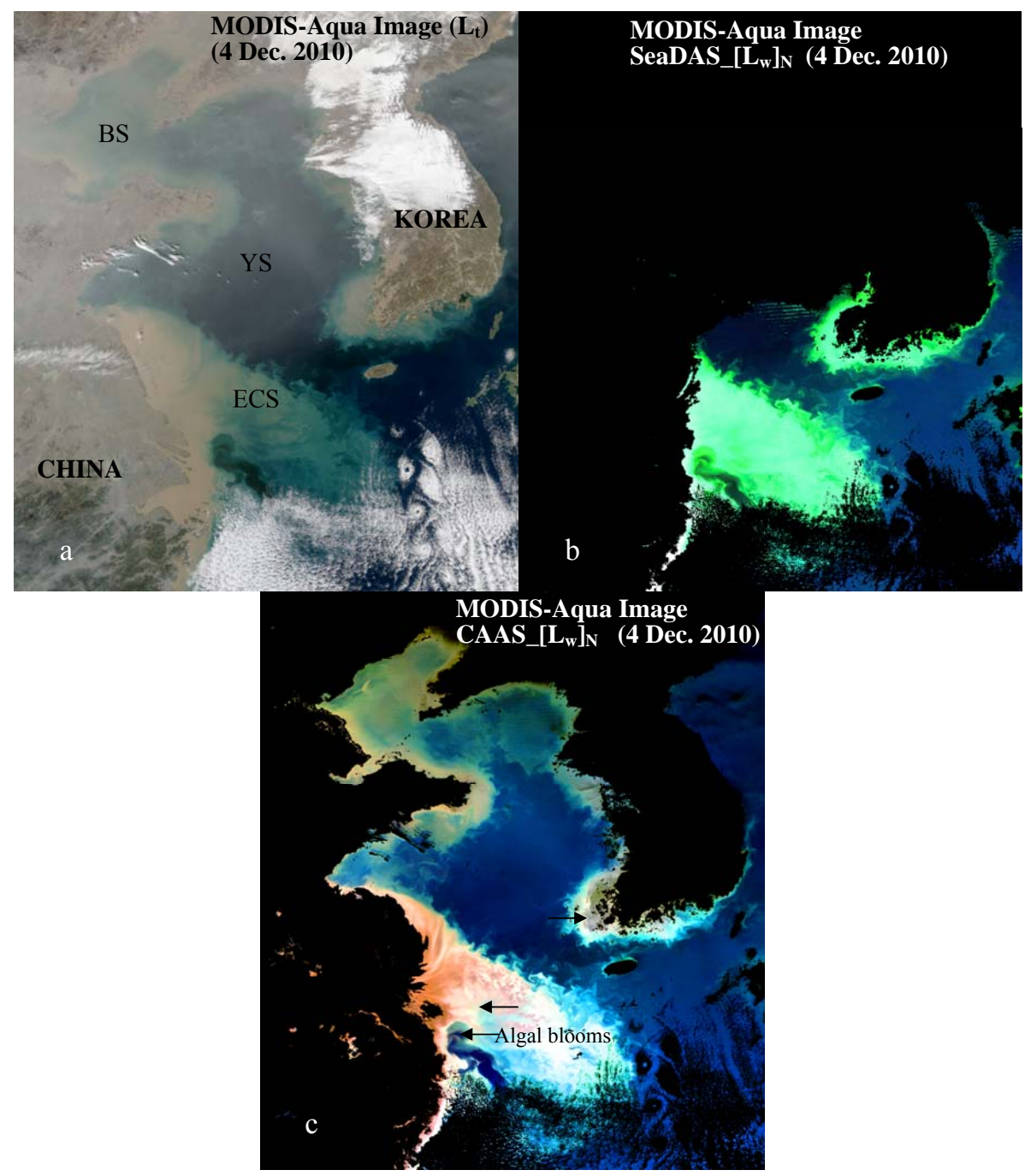

Fig. 3. MODIS-Aqua true colour composite image (4 December 2010) for the East China Sea (ECS), Yellow Sea (YS), Bogai Sea (BS) and waters around Korea generated from the total radiances at 443, 551 and $488 \mathrm{~nm}$ (B253) (a) and the corresponding water-leaving radiances from the SeaDAS algorithm (b) and CAAS algorithm (c).

\subsubsection{Aerosol analysis}

To understand the potential causes of biased negative $\left[L_{\mathrm{W}}\right]_{N}$ with the SeaDAS algorithm, aerosol radiances derived from MODIS-Aqua imagery of the Arabian Sea (18 February 2010) were examined for a group of pixels encompassing bloomed, turbid and relatively clear waters. No comparisons are presented here for typical Case 1 waters since the CAAS $L_{\mathrm{a}}$ and SeaDAS $L_{\mathrm{a}}$ for these waters had exceptionally good correlations $\left(R^{2} \cong 1\right)$ at all wavelengths. Scatter plots in Fig. 6 show the relationship between CAAS_ $L_{\mathrm{a}}$ and SeaDAS_ $L_{\mathrm{a}}$, wherein the dark colour cluster represents aerosol radiances calculated using Eqs. 4-6 ( $L_{\mathrm{rc}}$ as input) and the grey colour cluster represents aerosol radiances iteratively calculated using Eqs. (4)-(8) (with corrected $L_{\mathrm{a}}$ at NIR bands as input). Interestingly, there is a tight, linear relationship between CAAS_ $L_{\mathrm{a}}$ and SeaDAS_ $L_{\mathrm{a}}$ at 748 and $869 \mathrm{~nm}$ although slopes of the clusters in the visible domain are notably changed with respect to the water types and atmospheric conditions. Obvious is three groups of clusters in the visible domain, with the first one corresponding to dense blooms (low aerosol), the second one to relatively clear waters (fairly intense and non-uniform aerosol) and the third one to turbid waters (low and uniform aerosol) (see top right corner panel in Fig. 6). It should be noted that the SeaDAS algorithm led to gains in aerosol radiances for all the water types (mainly towards short wavelengths). However, the increase in aerosol radiance values is more pronounced for bloomed waters regardless of the low aerosols, and indicates that the aerosol radiance at 748 and $865 \mathrm{~nm}$ is overestimated by an inappropriate NIR correction scheme, which is apparently not sufficient to deal with enhanced contributions of 

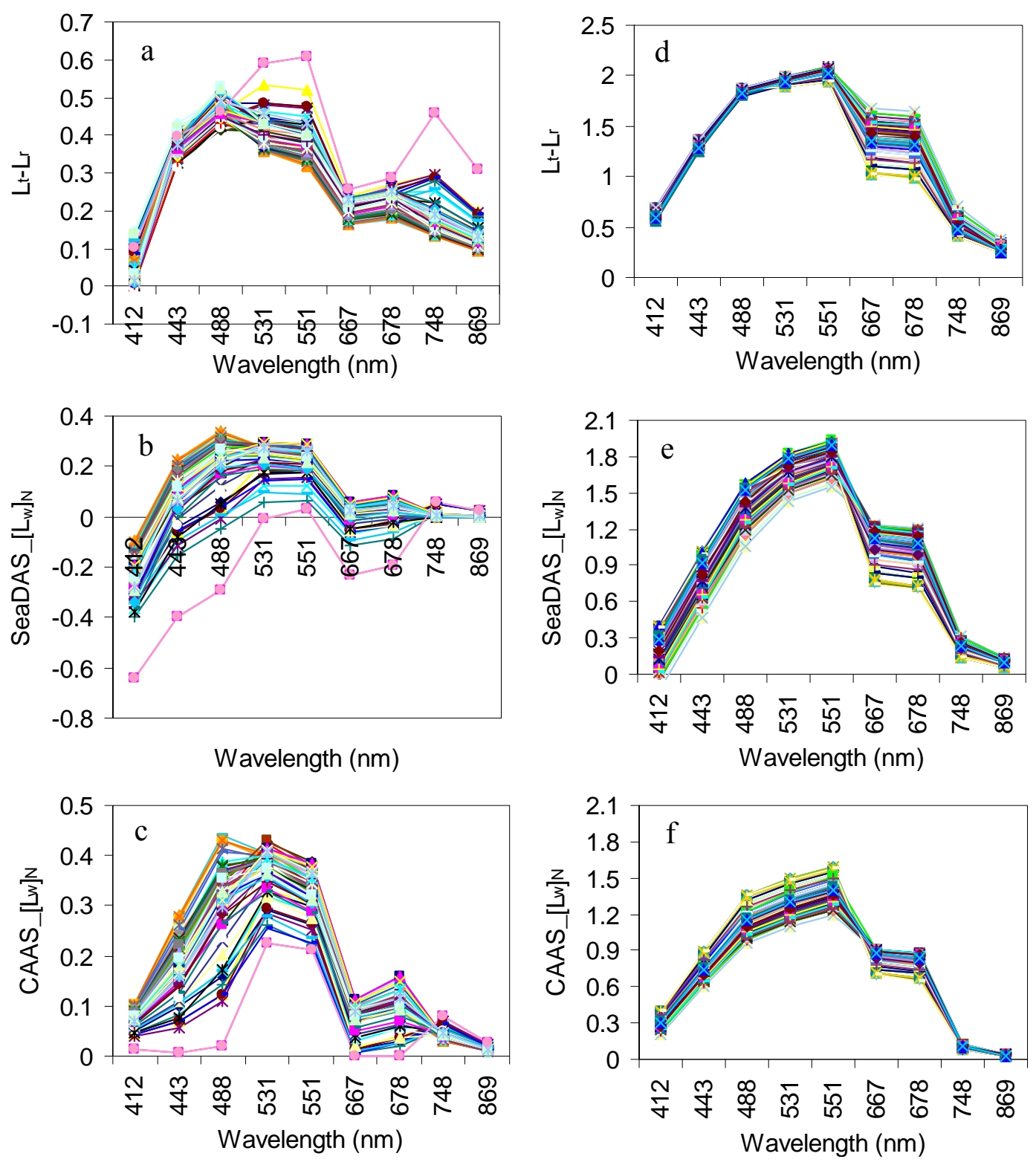

Fig. 4. Rayleigh-corrected $\left(L_{\mathrm{t}}-L_{\mathrm{r}}\right)$ and water-leaving radiance spectra $\left[L_{\mathrm{w}}\right]_{N}$ for intense algal bloom waters of the Arabian Sea (a)-(c) and turbid waters of the Korean Southwest Sea (d)-(f), obtained from MODIS-Aqua imageries (a-c: 18 February 2010; d-f: 4 December 2010) using the SeaDAS and CAAS algorithms. Locations are indicated in the corresponding MODIS-Aqua data (Figs. $2 \mathrm{~b}$ and $3 \mathrm{c}$ ).

algal blooms at these wavelengths (see in Fig. 4a). Gains in aerosol radiances (especially at $412-488 \mathrm{~nm}$ ) for turbid waters confirm the presence of scattering sediments in these waters. The effect of this significant increase in aerosol radiances toward the short wavelengths is clearly seen in the negatively biased water-leaving radiances of the SeaDAS algorithm for bloomed waters (see in Fig. 4b). By contrast, the CAAS produced slightly higher aerosol radiances for turbid waters, but such gains were significantly reduced by removing the near-infrared water signal at 748 and $865 \mathrm{~nm}$ through Eqs. (4)-(8).
The Arabian Sea is known to be caused by frequent algal blooms and strongly absorbing aerosols (mineral dust from adjacent deserts). The most essential distortions in $L_{\mathrm{w}}$ values are revealed in such conditions prevailing together, and are therefore completely discarded in the processing procedure together with ordinary atmospheric clouds, if the dust density is too high. Figure 7 shows the example of comparison between the SeaDAS-derived $L_{\mathrm{a}}(\lambda)$ and CAAS-derived $L_{\mathrm{a}}(\lambda)$ for the above conditions in the Arabian Sea. Clearly, the CAAS-derived $L_{\mathrm{a}}$ increases from 869 to $488 \mathrm{~nm}$ and decreases from 488 to $412 \mathrm{~nm}$ due to strong absorption of 

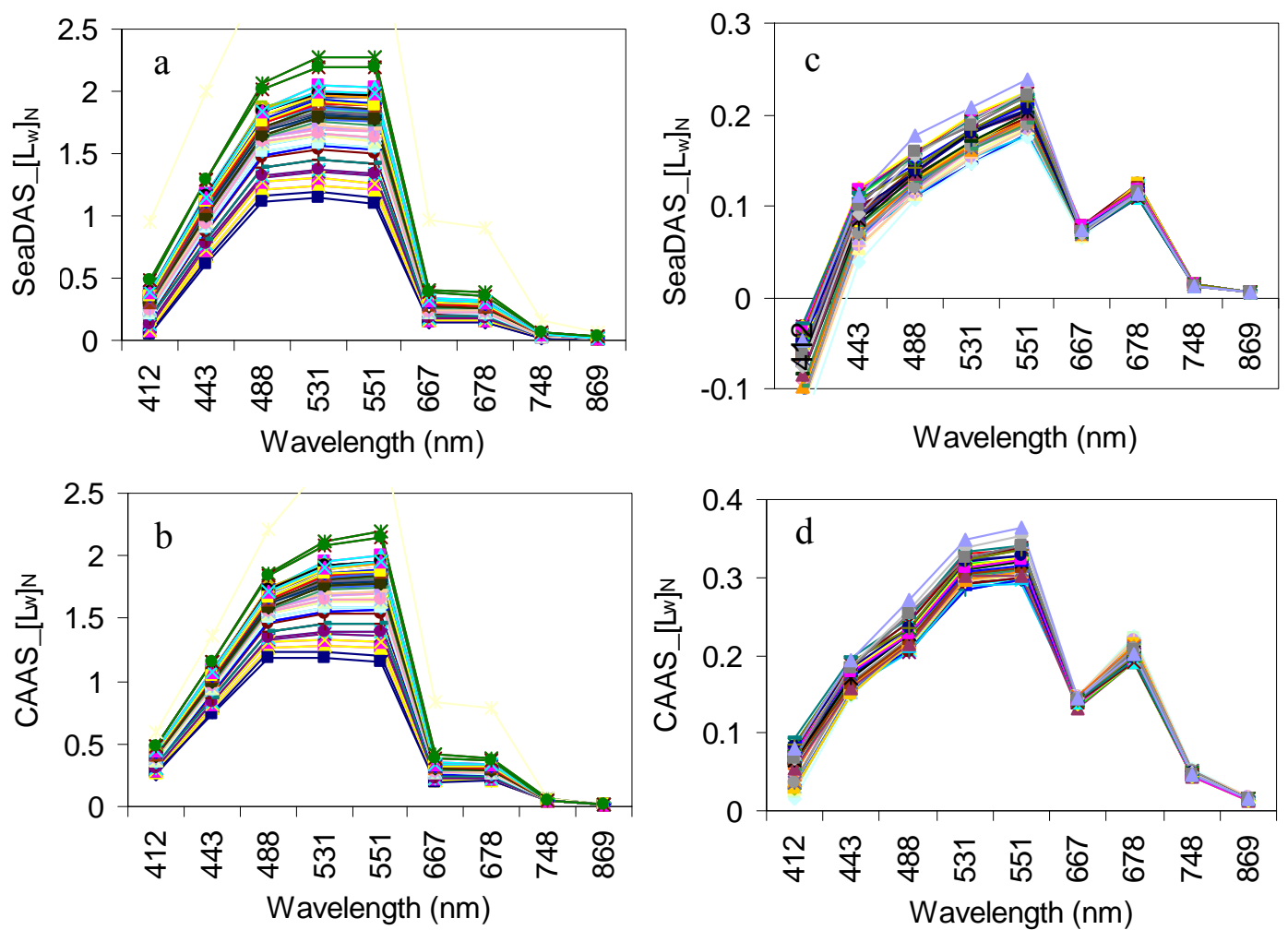

Fig. 5. Comparison of the water-leaving radiance spectra $\left[L_{\mathrm{w}}\right]_{N}$ for turbid waters (a)-(b) and algal bloom waters (c)-(d) obtained from MODIS-Aqua image (4 December 2010) using the SeaDAS and CAAS algorithms. These spectra are from bloom and turbid waters in the East China Sea (see arrow marks in Fig. 3c).

mineral aerosols (non-absorbing aerosols not shown because of their high $L_{\mathrm{a}}$ values suppressing the spectral variability of absorbing case). Note that a pronounced low $L_{\mathrm{a}}$ at $412 \mathrm{~nm}$ is the result of these aerosols. However, different spectral features in $L_{\mathrm{a}}(\lambda)$ are derived from the SeaDAS algorithm which are rather steadily increasing from 869 to $443 \mathrm{~nm}$ with a slight low at $412 \mathrm{~nm}$. These unrealistic $L_{\mathrm{a}}(\lambda)$ values eventually lead to an excessive correction in the violet-green wavelengths, which in turn result in large errors in chlorophyll retrieval from MODIS-Aqua data or discarding of such data in case of the higher dust density (Fig. $4 \mathrm{a}-\mathrm{c}$ and within circles in Fig. 10). Many similar data sets for the Arabian Sea from different periods were processed showing a lot of analogous results that confirm the existence of negative spatial and temporal correlation between SeaDAS $L_{\mathrm{w}}$ and $\tau_{\mathrm{a}}$ when the aforesaid conditions occur.

\subsubsection{Sun glint analysis}

Figure 8a shows a typical distribution of sun glint measured at $551 \mathrm{~nm}$ and confirms that the glint contaminated portion of the image extends across the bloomed region in the central Arabian Sea. Of importance is the spectral contribution. Figure $8 \mathrm{~b}$ shows the relative sun glint radiances for pixels within the box in Fig. 8a. The relative sun glint radiances in- crease with increasing wavelength and obvious is its strong contribution in the NIR, where the bands used for atmospheric correction are positioned. It is even much higher (at longer wavelengths) than the radiance caused by atmospheric molecule scattering. The corresponding water-leaving radiance image shown in Fig. 8c indicates that the CAAS algorithm definitely improved ocean colour retrieval for the pixels contaminated by sun glint. Furthermore, the CAAS algorithm was able to recover more areas which were previously masked or having erroneous values produced by the SeaDAS algorithm. This is apparent in their Chl- $a$ images as discussed in the later section. These results imply that the current model works well as long as the sun glint contribution does not fully contaminate the water signal that reaches a satellite sensor.

\subsection{Validation of the CAAS algorithm}

Because the quality of the atmospheric correction affects the quality of $\left[L_{\mathrm{w}}\right]_{N}$ which is key to the estimation of biophysical products, satellite-derived remote sensing reflectances were compared with in situ data (from the NOMAD database) collected in clear, turbid and bloom waters. These regions are optically less-moderately complex and not the regions of intense absorbing aerosols, therefore 

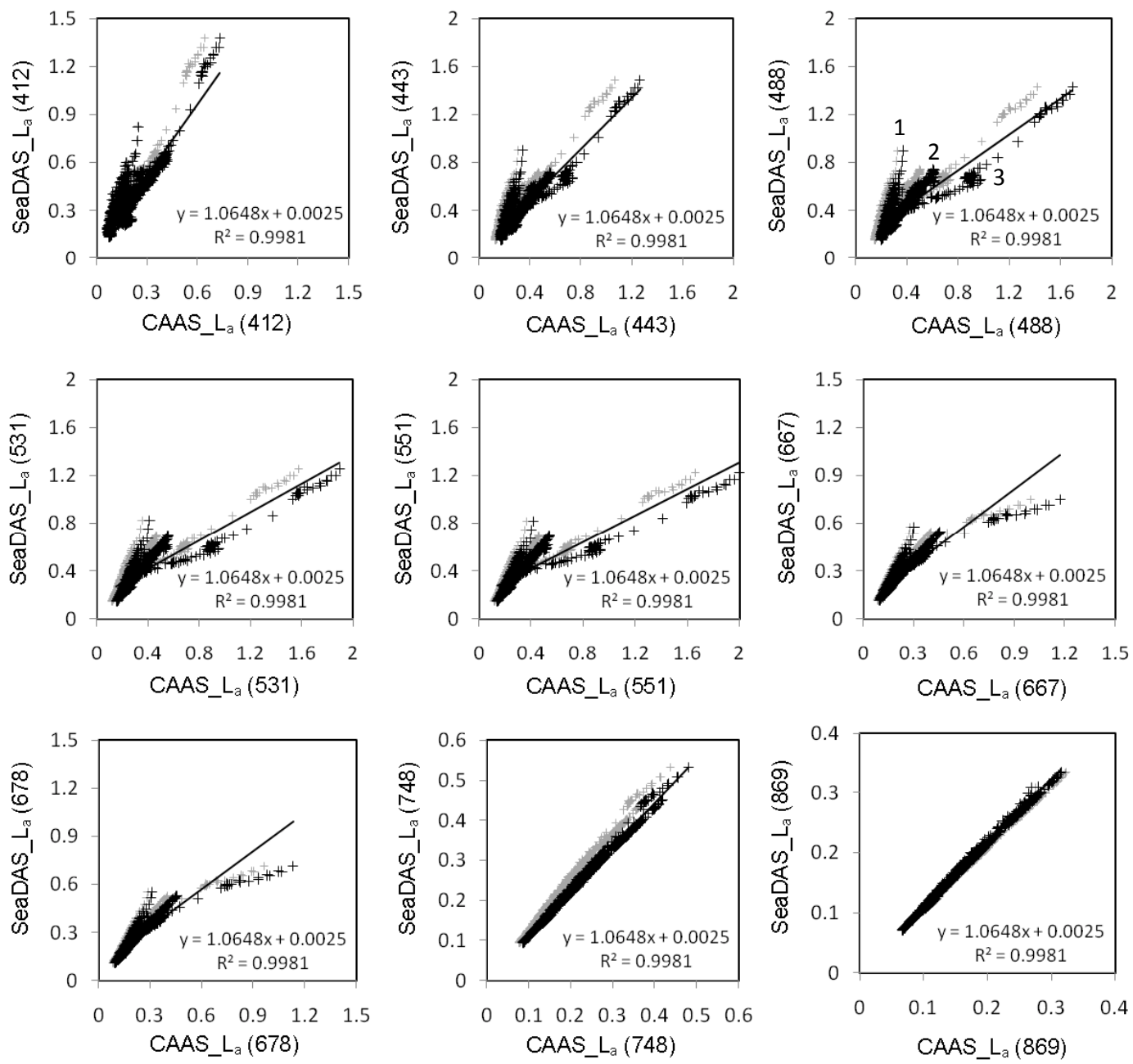

Fig. 6. Scatter plots of the CAAS retrieved $L_{\mathrm{a}}$ versus the SeaDAS retrieved $L_{\mathrm{a}}$ from MODIS-Aqua imagery (18 February 2010) in bloomed, turbid and relatively clear waters of the Arabian Sea.
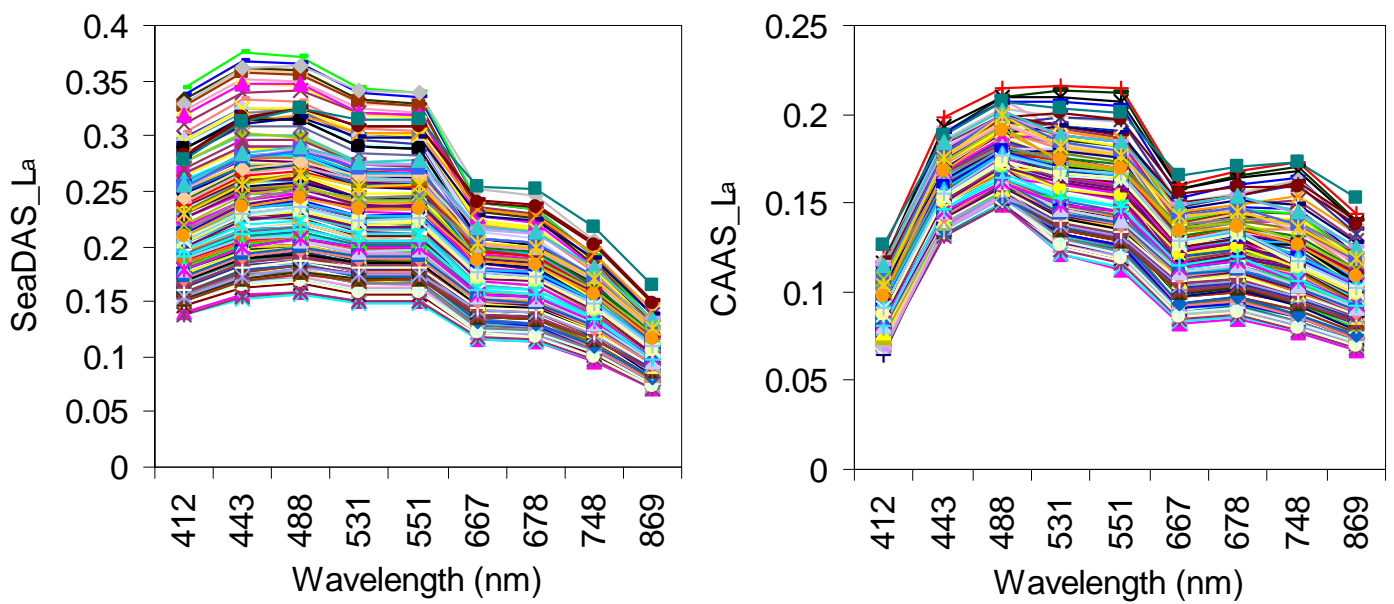

Fig. 7. Comparison of aerosol radiances derived from MODIS-Aqua imagery of bloomed waters of the Arabian Sea (18 February 2010) using the SeaDAS and CAAS algorithms. 


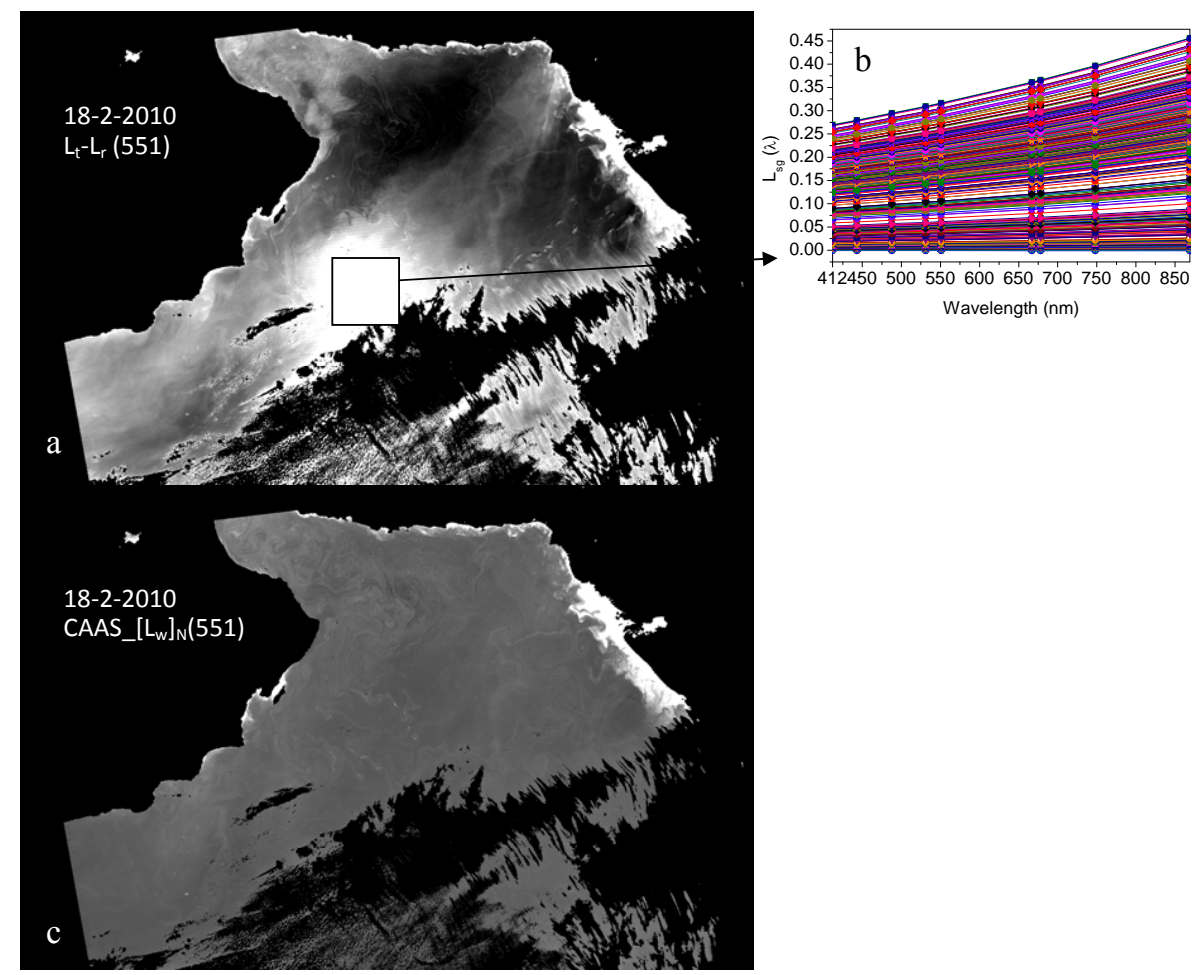

Fig. 8. Rayleigh-corrected radiance (a), sun glint spectra (b) and water-leaving radiance (c) from MODIS-Aqua imagery of 18 February 2010 (Arabian Sea) processed using the CAAS algorithm.

the SeaDAS algorithm produced probable positive $L_{\mathrm{w}}$ values. The results of applying the CAAS and SeaDAS algorithms to 55 matchups data are shown in the scatterplots (Fig. 9) and their corresponding statistics in Table 1. Interestingly, the $R_{\mathrm{rs}}$ values from the CAAS and SeaDAS algorithms are approximately aligned closer to the 1:1 line with respect to in-situ data at all wavelengths (except 412 and $667 \mathrm{~nm}$ ). The low $R_{\mathrm{rs}}$ values at $667 \mathrm{~nm}$ produced by the SeaDAS algorithm are erroneous and result in part from not fully taking into account that water-leaving radiance in the NIR. For clear waters the retrieval error of the CAAS algorithm is noticeable at $412 \mathrm{~nm}$ (few data points below the 1:1 line towards the higher end), and could be due to the added spectral variability of the atmospheric spectral models. On the other hand, the CAAS algorithm generated slightly higher water-leaving radiances at the longer wavelength $(667 \mathrm{~nm})$, but there was no data to confirm this. Because water absorption is expected to dominate the water signal at longer wavelengths and thus result in essentially black waters at NIR, the SeaDAS returned nearly the same as the in-situ water-leaving radiance and the magnitude of the discrepancy is therefore less remarkable in relatively clear waters (thus slightly better statistics). This demonstrates that in clear waters the SeaDAS algorithm might be a better option for atmospheric correction.

The impact of atmospheric correction on retrievals of pigment concentration was also studied with a Case 2 water bio- optical algorithm developed by Aiken et al. (1995). This simple band ratio algorithm relying on 488 and $551 \mathrm{~nm}$ bands is more suitable for optically complex waters since these bands are not much influenced by the constituents other than phytoplankton such as dissolved organic matter and suspended matter. Despite the limited number of observations at high chlorophyll regions, the regional matchups dataset confirms that the chlorophyll concentrations derived from $\mathrm{CAAS}_{-} R_{\mathrm{rs}}$ are better consistent with measured chlorophyll data than those derived from SeaDAS $R_{\mathrm{rs}}$. In moderately complex waters with $\mathrm{Chl} 2-6 \mathrm{mg} \mathrm{m}^{-3}$, an overestimation of chlorophyll by the SeaDAS algorithm is obvious simply because of the enhanced water signal interfering with the NIR scheme with this algorithm. Such an effect is minimised in chlorophyll from the CAAS $R_{\mathrm{rS}}$, with a MRE 4.29, RMSE 0.38, slope $0.847, R^{2} 0.53$ and bias -0.155 . The mean chlorophyll concentration for all 55 matchup data is $1.71 \mathrm{mg} \mathrm{m}^{-3}$ (in situ), $2 \mathrm{mg} \mathrm{m}^{-3}$ (CAAS), and $2.3 \mathrm{mg} \mathrm{m}^{-3}$ (SeaDAS).

\subsection{Application to MODIS-Aqua imagery}

The Aiken bio-optical algorithm was applied to few MODISAqua images of the Arabian Sea acquired during different bloom periods to further exemplify schematically the impact of atmospheric correction on pigment retrievals. Figure 10 shows that the band ratio algorithm applied to the inappropriately corrected for atmosphere signal (SeaDAS) 

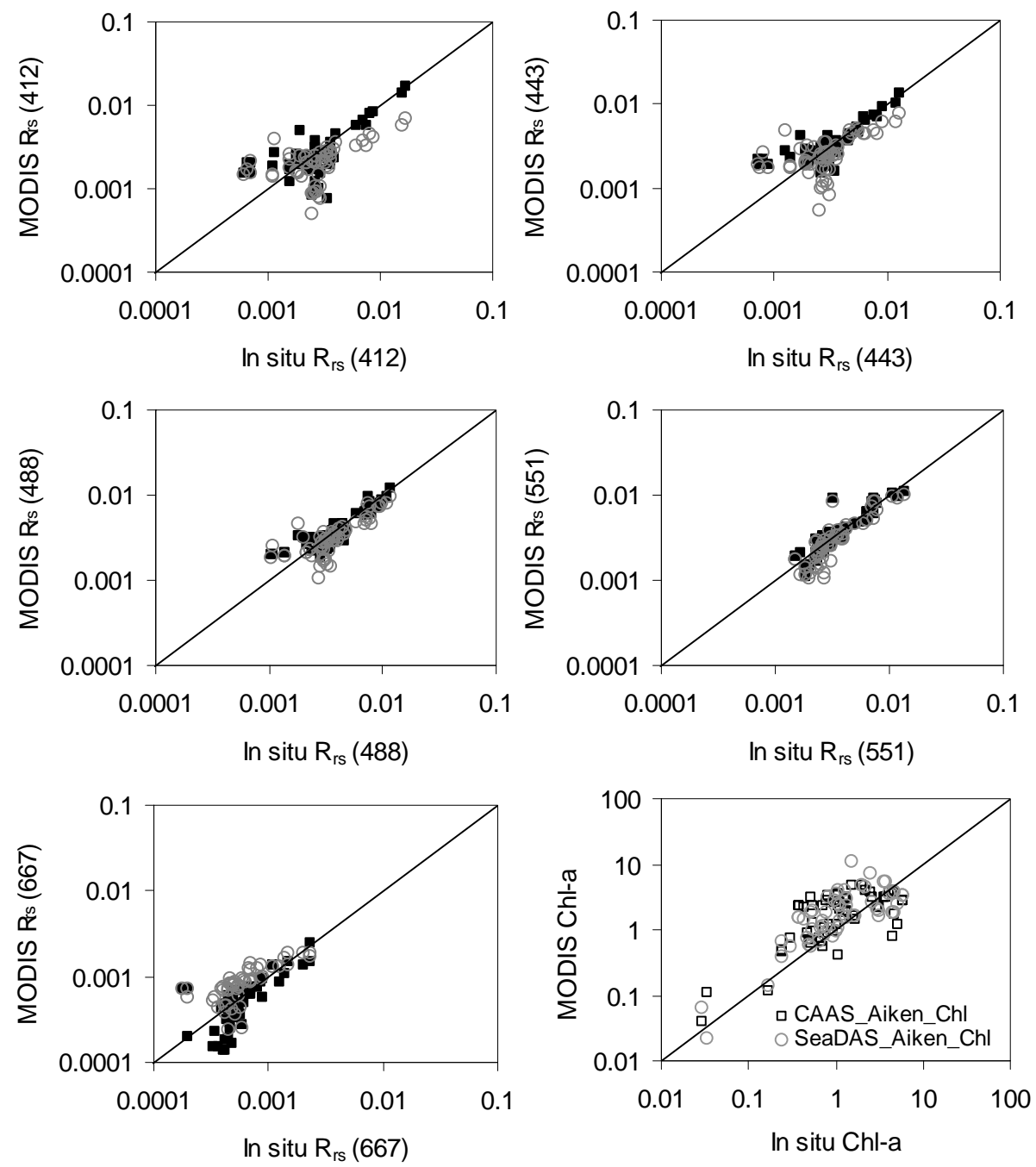

Fig. 9. Comparison of in situ measurements of the remote sensing reflectance with coincident MODIS-Aqua spectra (from various regional waters) from the SeaDAS and CAAS algorithms. The Chl- $a$ concentrations retrieved from the Aiken bio-optical algorithm using CAAS $R_{\mathrm{rs}}$ and SeaDAS $R_{\mathrm{rs}}$ are shown in the bottom-right corner panel.

resulted in inaccurate, overestimated (often $>30 \mathrm{mg} \mathrm{m}^{-3}$ in offshore patches of blooms) and spatially homogeneous chlorophyll in highly bloomed regions, where no field observations showed values in excess of $30 \mathrm{mg} \mathrm{m}^{-3}$. A re-analysis of the same data using the present CAAS algorithm shows substantial improvements. In particular, nearly all of the excessive $\mathrm{Chl}$ retrievals have been corrected and the spatial patterns in algal blooms are more realistic. It is also evident that some coastal turbid features (indicated by an arrow mark on the 23 November 2008 image) are captured with very high chlorophyll concentrations, which is an indication of the atmospheric correction failure meaning that the signal is over corrected for the atmosphere. However, the CAAS algorithm seems to suppress such features by means of producing realistic $L_{\mathrm{w}}$ spectra. The atmospheric correction failure in bloomed waters (negative $L_{\mathrm{w}}(\lambda)$ values) is primarily due to the fact that waters containing large accumulations of algal matters have a relatively strong water-leaving radiance in the near-infrared bands (as evident in Fig. 4 left panels), while at the same time are absorbing strongly in the blue green domain, which leads to possible errors in the atmospheric correction and underestimation of $L_{\mathrm{w}}(\lambda)$ in the blue and green bands of MODIS-Aqua, which appears as an elevated pigment concentration (Siegel et al., 2000). Chlorophyll data are completely discarded in the SeaDAS processing procedure together with ordinary clouds, when density of algal blooms (and absorbing aerosols) is too high (see the black and fagged regions/pixels within circles in Fig. 10 left panels). The erroneous data in the strong sun glint regions (indicated by arrow marks in left panels of Fig. 10) are also flagged out by the SeaDAS algorithm. These algal blooms and sun glint pixels previously flagged out by that algorithm are successfully 


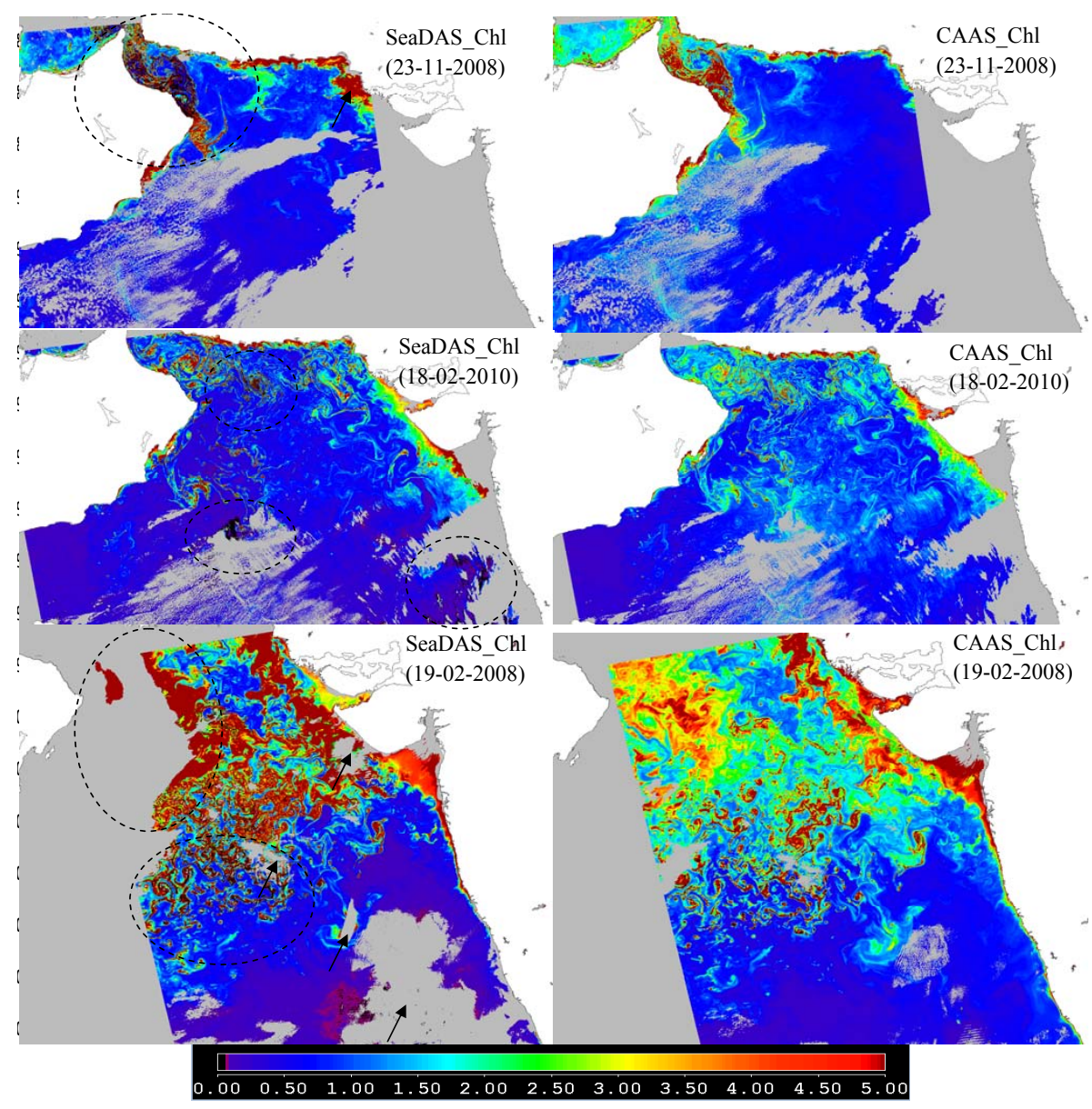

Fig. 10. Chlorophyll concentrations derived from the Aiken Case 2 bio-optical algorithm using MODIS-Aqua derived remote sensing reflectances from the SeaDAS and CAAS algorithms.

recovered with the more realistic spatial features consistent with the adjacent regions. In case of clear oceanic waters, the magnitude of chlorophyll signal is nearly the same for both the algorithms suggesting not much impact of the atmosphere correction on the ratio of signal magnitudes at bluegreen bands.

\subsection{Implications for the Geostationary Ocean Colour Imager (GOCI)}

In comparison with open ocean applications, coastal applications involving phenomena that vary on shorter space and time scales demand a simultaneous increase in spatial and temporal resolution. The geostationary ocean colour imager such as the GOCI (currently providing data for ECS, YS, ES and Korean waters) has a unique capability to observe the ocean and coastal waters with high spatial resolution $(500 \mathrm{~m})$, very high temporal resolution (refresh rate: $1 \mathrm{~h}$ ) and spectral resolution similar with MODIS-Aqua (Shanmugam and Ahn, 2007b). Such sensors are capable of detecting, monitoring, and predicting short term and regional oceanic phenomena such as red tides, yellow dust, fishing ground information (Shanmugam et al., 2008). As shown in Fig. 3, coastal and open ocean waters around Korea are optically more complex and an over-correction is often inevitable with the SeaDAS algorithm. The situation is even worse when an excessive over-correction changes the sign from positive to negative between adjacent pixels (e.g. from an "algae" or "turbid" pixel to a "water" pixel) and between scenes within a short interval of time $(1 \mathrm{~h})$. Such errors are further magnified if one attempts to merge consequent scenes acquired on the same day in order to support certain oceanographic analyses. The current CAAS provides an effective means to remove atmospheric effects and retrieve physically realistic water-leaving radiances in these complex waters that are often affected by strong aerosol conditions. The data from the CAAS algorithm are also stable in the sense that changes in water-leaving radiances resulting from this algorithm are less than the variability among adjacent pixel spectra, which is not the case with the SeaDAS algorithm. 


\section{Summary and conclusions}

The direct application of the SeaDAS algorithm yields excessive errors in retrieved water-leaving radiance and biophysical products in complex waters (likely due to overestimation of $L_{\mathrm{a}}+L_{\mathrm{ra}}$ in the visible and thus reduction in $L_{\mathrm{w}}$ there which appears as an elevated pigment concentration). The principal difficulty in these waters is:

1. The adequacy of aerosol models is presently difficult to judge. This holds true for mineral dust aerosols (from deserts) because their absorption can seriously reduce $L_{\mathrm{a}}+L_{\mathrm{ra}}$ in the visible and their vertical distribution profoundly influences the TOA radiance in the visible (especially in the blue) (Gordon, 1997; Moulin et al., 2001). Moreover, the absorption properties are very difficult to determine on the basis of the observations of $L_{\mathrm{a}}+L_{\mathrm{ra}}$ in the NIR which means that in-situ measurements in the visible are required for correction. However, in the visible (especially blue) $L_{\mathrm{W}}$ can be significant, and cannot be estimated a priori (Gordon, 1997).

2. The errors involved in extrapolating aerosol reflectance to visible bands are considerably higher and this may require a more realistic method (Ruddick et al., 2000).

3. Assumption of negligible water-leaving radiance in the NIR is not valid in complex waters, as high SS loads and phytoplankton will contribute NIR radiance (Arnone et al., 1998; Siegel et al., 2000; Ruddick et al., 2000).

4. Difficulty in dealing with highly turbid atmosphere that is presently considered as the "high aerosol" and is masked when $\tau_{\mathrm{a}}(869)>0.4$ (Robinson et al., 2003).

5. Because of the difficulty in removing sun glint, the TOA sun glint radiance $T(\lambda) . L g(\lambda)$ is mostly masked out and residual contamination is corrected based on a model of sea surface slope distribution (Wang and Bailey, 2001). Consequently, the criteria used in points 4 and 5 lead to a tremendous loss of information for ocean colour work.

6. Although modifications to point 3 (i.e. "non-zero $L_{\mathrm{w}}$ in the NIR" based on in-water models and spatial homogeneity assumption; Arnone et al., 1998; Siegel et al., 2000; Ruddick et al., 2000; Hu et al., 2000) show noticeable improvements in turbid waters, problems are still encountered in highly bloomed waters and could be attributed to inadequacy of aerosol models as stated in points 1 and 2. As evident in Figs. 2, 3 and 10 (true colour composite not shown here), many assumptions regarding aerosols are invalidated because of their strong diversity and compositional changes across these regions.

Many of the above properties can indeed be derived in the whole spectrum of ocean colour solely from a knowledge of the total and Rayleigh-corrected radiances, and that possibility has been developed in detail within the framework of the CAAS algorithm that makes no use of ancillary parameters. This algorithm has been tested with MODIS-Aqua images of optically very complex waters in the Arabian Sea and around Korea and with in-situ measurements of the remote sensing reflectance and $\mathrm{Chl}$ concentrations in various regional waters. The new algorithm shows promise in dealing with the diversity and variability of aerosols and strong sun glint patterns, and produces more realistic spatial structures in waterleaving radiance maps as well as positive water-leaving radiance for all visible bands, whereas the SeaDAS algorithm yields significantly lower $L_{\mathrm{w}}$ (often negative $L_{\mathrm{w}}$ at $412 \mathrm{~nm}$ ) in highly turbid waters and unphysical negative $L_{\mathrm{w}}$ at many wavelengths in highly bloomed waters. A clear underestimation of $L_{\mathrm{w}}$ with increasing error toward lower wavelengths is typical of excessive aerosol path radiance removal. Furthermore, the spatial patterns previously masked by the SeaDAS algorithm in the sun glint contaminated and strong aerosol regions are successfully recovered by the CAAS algorithm. It was noted that CAAS returns slightly low $L_{\mathrm{w}}$ at $412 \mathrm{~nm}$ and high $L_{\mathrm{w}}$ at 667 and $678 \mathrm{~nm}$ especially for clear waters. Nevertheless, the spectral form is still well produced by this algorithm at 667 and $678 \mathrm{~nm}$ that allows accurate measurements of the fluorescence light height above the background between $667 \mathrm{~nm}$ and $748 \mathrm{~nm}$ using a baseline method (Abbott and Letelier, 1999; Ahn and Shanmugam, 2007). Also, our analysis shows that the retrieved pigment concentrations with CAAS algorithm are more realistic than those derived with the SeaDAS algorithm, suggesting its practical utility for ocean colour applications in complex waters.

The results further suggest that the CAAS algorithm is an alternative correction scheme to process ocean colour imagery in the presence of sun glint and strong aerosols (e.g. yellow dust). Though the algorithm has been described in the context of MODIS-Aqua imagery, it can be applied rather generally to other satellite-based and probably also airborne ocean colour sensors. The directions for further research include a more detailed validation of this algorithm with large in-situ datasets from highly turbid and productive waters and an attempt to tune it to have a wider applicability.

Acknowledgements. This work was supported by grants from the Korean Ocean Research and Development Institute (KORDI), Korea (No. OEC/10-11/101/KORD/PSHA). The author gratefully acknowledges the NASA Ocean Biology Processing Group for making available the global, high quality in situ bio-optical (NOMAD) dataset as well as the LAC MODIS-Aqua data to this study. The author is indebted to the three anonymous reviewers for their constructive comments and recommendations.

Topical Editor P. Drobinski thanks three anonymous referees for their help in evaluating this paper. 


\section{References}

Abbott, M. R. and Letelier, R. M.: ATBD 22-Chlorophyll Fluorescence, NASA Algorithm Theoretical Basis Document, http: //modis.gsfc.nasa.gov/data/atbd/atbd_mod22.pdf, 1999.

Ahn, Y. H. and Shanmugam, P.: Derivation, analysis of the fluorescence algorithms to estimate chlorophyll a concentrations in ocean waters. Journal of Optics A: Pure, Appl. Optics, 9, 352$362,2007$.

Aiken, J., Moore, G. F., Trees, C. C., Hooker, S. B., and Clark, D. K.: The SeaWiFS CZCS-type pigment algorithm, in: SeaWiFS Technical Report Series, vol. 29, edited by: Hookerm S. B. and Firestonem E. R., Goddard Space Flight Center, Greenbelt, MD, 1995.

Amin, R., Gilerson, A., Zhou, J., Gross, B., Moshary, F., and Ahmed, S.: Impacts of Atmospheric Corrections on Algal Bloom Detection Techniques. Eighth Conference on Coastal Atmospheric, Oceanic Prediction, Processes, USA, 2009.

Arnone, R. A., Martinolich, P., Gould, R. W., Stumpf, R., and Ladner, S.: Coastal optical properties using SeaWiFS, presented at Ocean Optics XIV Conference, Kailua-Kona, Hawaii, Ocean Optics XIV, Washington, D.C., 1998.

Carder, K. L., Chen, F. R., Lee, Z., Hawes, S. K., and Cannizzaro, J. P.: MODIS Ocean Science Team Algorithm Theoretical Basis Document, ATBD 19, Case 2 Chlorophyll a, version 7, http:// modis.gsfc.nasa.gov/data/atbd/atbd_mod19.pdf, 2003.

Coppin, P. R. and Bauer, M. E.: Processing of multi-temporal L,sat TM imagery to optimize extraction of forest cover change features, IEEE Trans. Geosci. Remote Sens., 32, 918-927, 1994.

Doerffer, R., Schiller, H., Fischer, J., Preusker, R., and Bouvet, M.: The impact of sun glint on the retrieval of water, parame., Proc. of the 2nd MERIS (A) ATSR User Workshop, Frascati, Italy, 2008.

Gomes, H. R., Goes, J. I., Matondkar, S. G. P., Parab, S. G., AlAzri, A. R. N., and Thoppil, P. G.: Blooms of Noctiluca miliaris in the Arabian Sea-An in situ, satellite study, Deep Sea Res. Part I., 55, 751-765, doi:10.1016/j.dsr.2008.03.003, 2008.

Gordon, H. R.: Atmospheric correction of ocean colour imagery in the Earth Observing System era, J. Geophys., 102, 17081-17106, 1997.

Gordon, H. R. and Voss, K. J.: MODIS Normalized Water leaving Radiance Algorithm Theoretical Basis Document, University of Miami, USA, 1999.

Gordon, H. R. and Wang, M.: Surface Roughness Considerations for Atmospheric Correction of Ocean Colour Sensors. 1: The Rayleigh Scattering Component, Appl. Optics, 31, 4247-4260, 1992.

Gordon, H. R. and Wang, M.: Retrieval of water-leaving radiance, aerosol optical thickness over the oceans with SeaWiFS: a preliminary algorithm, Appl. Optics, 33, 443-452, 1994.

Gordon, H. R., Brown, O. B., and Evans, R. H.: Exact Rayleigh scattering calculations for use with the Nimbus-7 Coastal Zone Colour Scanner, Appl. Optics, 27, 862-871, 1988.

Hooker, S. B., Esaias, W. E., Feldman, G. C., Gregg, W. W., and McClain, C. R.: SeaWiFS Technical Report Series vol 1, An overview of SeaWiFS, Ocean Colour, NASA Technical Memorandum, 104566, 1992.

$\mathrm{Hu}, \mathrm{C}$. : A novel ocean colour index to detect floating algae in the global oceans, Remote Sens. Environ., 113, 2118-2129, 2009.

Hu, C., Carder, K. L., and Muller-Karger, F. E.: Atmospheric correction of SeaWiFS imagery over turbid waters: a practical ap- proach, Remote Sens. Environ., 74, 195-206, 2000.

Hwang, P. and Shemdin, O.: The Dependence of Sea-Surface Slope on Atmospheric Stability, Swell Conditions, J. Geophys. Res., 93, 13903-13912, 1988.

Kay, S., Hedley, J. D., and Lavender, S.: Sun Glint Correction of High, Low Spatial Resolution Images of Aquatic Scenes: a Review of Methods for Visible , Near-Infrared Wavelengths, Remote Sens., 1, 697-730, doi:10.3390/rs1040697, 2009.

Koepke, P.: Effective reflectance of oceanic whitecaps, Appl. Optics, 23, 1816-1824, 1984.

Lavender, S. J., Pinkerton, M. H., Moore, G. F., Aiken, J., and Patissier, D. B.: Modification to the atmospheric correction of SeaWiFS ocean colour images over turbid waters, Cont. Shelf Res., 25, 539-555, 2005.

Li, L. P., Fukushima, H., Frouin, R., Mitchell, B. G., He, M. X., Uno, I., Takamura, T., and Ohta, S.: Influence of submicron absorptive aerosol on SeaWiFS-derived marine reflectance during ACE-Asia, J. Geophys. Res., 108, AAC 13-1_AAC 13-6, 2003.

Mélin, F., Zibordi, G., and Djavidnia, S.: Development, validation of a technique for merging satellite derived aerosol optical depth from SeaWiFS, MODIS, Remote Sens. Environ., 108, 436-450, 2007.

Moulin, C., Gordon, H. R., Banzon, V. F., and Evans. R. H.: Assessment of Saharan dust absorption in the visible from SeaWiFS imagery, J. Geophys. Res., 106, 18239-18249, 2001.

Nobileau, D. and Antoine, D.: Detection of blue-absorbing aerosols using near infrared, visible (ocean colour) remote sensing observations, Remote Sens. Environ., 95, 368-387, 2005.

O'Reilly, J. E., Maritorena, S., Mitchell, B. G., Siegel, D. A., Carder, K., Garver, S. A., Kahru, M., and McClain, C.: Ocean colour algorithms for SeaWiFS, J. Geophys. Res., 103, 937-953, doi:10.1029/98JC02160, 1998.

Otero, M. P. and Siegel, D. A.: Spatial, temporal characteristics of sediment plumes, phytoplankton blooms in the Santa Barbara Channel, Deep Sea Res., Part II., 51, 1139-1149, 2004.

Robinson, W. D., Franz, B. A., Patt, F. S., Bailey, S. W., and Werdell, P. J.: Masks, flags updates, SeaWiFS Postlaunch Technical Report Series, NASA Tech. Memo, 206892, 2003.

Ruddick, K. G., Ovidio, F., and Rijkeboer, M.: Atmospheric correction of SeaWiFS imagery for turbid coastal and inland waters, Appl. Optics, 39, 897-913, 2000.

Shanmugam, P. and Ahn, Y. H.: New atmospheric correction technique to retrieve the ocean colour from SeaWiFS imagery in complex coastal waters, Journal of Optics A: Pure, Applied Optics, 9, 511-530, 2007a.

Shanmugam, P. and Ahn, Y. H.: Reference solar irradiance spectra and consequences of their disparities in remote sensing of the ocean colour, Ann. Geophys., 25, 1235-1252, doi:10.5194/angeo-25-1235-2007, 2007b.

Shanmugam, P., Ahn, Y. H., and Ram, P. S.: SeaWiFS sensing of hazardous algal blooms, their underlying physical mechanisms in shelf-slope waters of the Northwest Pacific during summer, Remote Sens. Environ., 112, 3248-3270, 2008.

Siegel, D. A., Wang, G. M., Maritorena, S., and Robinson, W.: Atmospheric correction of satellite ocean colour imagery: the black pixel assumption, Appl. Optics, 39, 3582-3591, 2000.

Siegel, D. A., Maritorena, S., Nelson, N. B., Hansell, D. A., and Lorenzi-Kayser, M.: Global distribution, dynamics of coloured dissolved, detrital organic materials, J. Geophys. Res., 107, 
3228, doi:10.1029/2001JC000965, 2002.

Song, C., Woodcock, C. E., Seto, K. C., Lenney, M. P., and Macomber, S. A.: Classification, change detection using L,sat TM data: when , how to correct atmospheric effects?, Remote Sens. Environ., 75, 230-244, 2000.

Stumpf, R. P., Culver, M. E., Tester, P. A., Tomlinson, M., Kirkpatrik, G. J., Pederson, B. A., Truby, E., Ransibrahmanakul, V., and Soracco, M.: Monitoring Karenia brevis blooms in the Gulf of Mexico using satellite ocean colour imagery, other data, Harmful Algae, 2, 147-160, 2003.

Wang, M.: A sensitivity study of the SeaWiFS atmospheric correction algorithm: effects of spectral b, variations, Remote Sens. Environ., 67, 48-59, 1999.

Wang, M. and Bailey, S.: Correction of the sun glint contamination on the SeaWiFS ocean, atmosphere products, Appl. Optics, 40, 4790-4798, 2001.

Wang, M. and Shi, W.: The NIR-SWIR combined atmospheric correction approach for MODIS ocean colour data processing, Optics Express, 15, 15722-15733, 2007.
Werdell, P. J. and Bailey, S. W.: An improved in-situ bio-optical data set for ocean colour algorithm development, satellite data product validation, Remote Sens. Environ., 98, 122-140, 2005.

Werdell, P. J., Franz, B. A., and Bailey, S. W.: Evaluation of shortwave infrared atmospheric correction for ocean colour remote sensing of Chesapeake Bay, Remote Sens. Environ., 114, 22382247, 2010.

Xianqiang, H., Delu, P., and Zhihua, M.: Atmospheric correction of SeaWiFS imagery for turbid coastal and inland waters, Chinese Society of Oceanography, 23, 609-615, 2004.

Yan, B., Stamnes, K. W. Li., Chen, B., Stamnes, J. J., and Si-Chee Tsa: Pitfalls in atmospheric correction of ocean colour imagery: how should aerosol optical properties be computed?: reply to comment, Appl. Optics, 42, 545-549, 2003. 